\title{
HARD CASES: A PROCEDURAL APPROACH
}

\author{
Jaap C. Hage \\ University of Limburg, P.O. Box 616, 6200 MD Maastricht, Netherlands \\ phone +31 43 883020, e-mail: jaap.hage@ metajur.rulimburg.nl

\section{Ronald Leenes} \\ University of Twente, P.O. Box 217, 7500 AE Enschede, Netherlands \\ phone: +31 53 892616, e-mail: romix@bsk.utwente.nl
}

\section{Arno R. Lodder}

University of Limburg, P.O. Box 616, 6200 MD Maastricht, Netherlands

phone +31 43 883005, e-mail: arno.lodder@metajur.rulimburg.nl

\begin{abstract}
Much work on legal knowledge systems treats legal reasoning as arguments that lead from a description of the law and the facts of a case, to the legal conclusion for the case. The reasoning steps of the inference engine parallel the logical steps by means of which the legal conclusion is derived from the factual and legal premises. In short, the relation between the input and the output of a legal inference engine is a logical one. The truth of the conclusion only depends on the premises, and is independent of the argument that leads to the conclusion.

This paper opposes the logical approach, and defends a procedural approach to legal reasoning. Legal conclusions are not true or false independent of the reasoning process that ended in these conclusions. In critical cases this reasoning process consists of an adversarial procedure in which several parties are involved. The course of the argument determines whether the conclusion is true or false. The phenomenon of hard cases is used to demonstrate this essential procedural nature of legal reasoning.

Dialogical Reason Based Logic offers a framework that makes it possible to model legal dialogues. We use Dialogical Reason Based Logic to specify hard cases in dialogical terms. Moreover, we analyse an actual Dutch hard case in terms of Dialogical Reason Based Logic, to demonstrate both the possibilities and the shortcomings of this approach.

It turns out that there is no one set of rational dialogue rules. There are many concurring sets of rules that govern particular types of dialogues. The rules for legal procedures are as much part of the law as the more substantial rules. As a consequence, it is not possible to offer an universal set of dialogue rules. Dialogical Reason Based Logic rather provides a framework which can be filled with dialogue rules that determine which dialogues are valid and which ones are invalid.
\end{abstract}




\section{INTRODUCTION}

What would you do if you were facing an important lawsuit and your case seems hopeless? You would hire a good lawyer! Because a good lawyer may be able to argue that your case is not simply lost, but, on the contrary, exemplifies so many legal snags that it may be decided either way, including your way. In short, a good lawyer can show a seemingly clear case to be actually a hard one.

Does this mean that a good lawyer has better knowledge of the law and therefore 'sees' that the case actually is a hard one, although less gifted lawyers might wrongly take it for a clear one? We think not. In our opinion the arguments of the good lawyer turn the case from a clear one into a hard one. Whether a case is clear or hard not only depends on the case and the law, but also on the arguments produced for both sides of the case. Whether a case is clear or hard, depends on the reasons actually adduced in defence of its various possible solutions.

This observation in our opinion illustrates an essential characteristic of the law, that is often neglected. What the law is in a particular case, is not independent of the procedure that leads to its determination. That cases are not hard or clear by themselves, but are made hard or clear, is only an illustration of this essential characteristic. In this paper we will use the phenomenon of hard cases to illustrate the purely procedural nature of the law.

With regard to hard cases, we must distinguish between their nature and their causes. The nature of hard cases is what makes a case a hard one by definition. The cause of a hard case is what causes the conditions of the definition to be fulfilled ${ }^{1}$. Assume, for instance, that a rule is open textured. This may lead to problems of a particular type for the solution of the case. The fact that there are problems of this particular type (and that they are solved in a particular manner), no matter how they are caused, is why the case a hard one. The existence of the problems concerns the nature of hard cases; while the cause of the problems is, as a consequence, the cause of the hardness ${ }^{2}$.

Anticipating a more elaborated answer, hard cases can provisionally be defined as those in which the parties involved in their solution are forced into an a-rational decision making process. This definition contains two elements. The first one is that an a-rational decision making process is involved in the solution of the case. It is the decision making process that determines whether a case is hard; hardness is not solely a logical property of the combination of a case and the law.

1 If the distinction between nature and cause is applied to beauty, we may say that the nature of beauty is a high ranking on an aesthetic scale, while the causes of beauty are the characteristics of e.g. a picture that make the picture rank high on an aesthetic scale.

2 It is also possible to distinguish between hard cases and difficult cases. Experienced lawyers are often able to solve cases without much thinking. They immediately seem to 'see' the solution. Sometimes, however, these same lawyers need to give a case a closer look, even if that look in the end results in a strong opinion on the correct solution. Some cases are difficult to solve, even if they have an unique solution. A possible explanation of this phenomenon is that the knowledge needed to solve difficult cases has not yet been chunked, in contrast to the knowledge used to solve simple cases (cf. Newell 1990, p. 6 f.).

It will be clear that a case which is difficult in the sense that its solution asks for extensive mental processing, differs from a case which is hard because there seems to be no unique legal solution. Hard cases will often be difficult ones, but there is a distinction. The difficulty of a case has to do with the psychological characteristics of the problem-solver in relation to the case, while hardness seems to be independent of the person considering the case. 
The second element is that the parties were forced to take an a-rational procedure. Whether a case is hard is not up to the discretion of the parties, although the behaviour of the parties is a factor in determining whether a case is hard. The factors that force the parties to take an a-rational procedure will turn out to be for a large part (but not solely) logical ones.

Our argument, which argues and elaborates our definition of hard cases, runs as follows. We start with a discussion of the procedural nature of the law, and the consequences that it has for legal knowledge systems. Second we describe Dialogical Reason Based Logic, which will serve as the framework for a more precise analysis of legal procedure in general, and hard cases in particular. This description includes an analysis of hard cases in terms of dialogue steps. Then we apply the framework of Dialogical Reason Based Logic to the case of the post-traumatic neurosis, an actual Dutch hard case. This application on the one hand illustrates the capabilities of the dialogical approach, and on the other hand makes it clear why Dialogical Reason Based Logic can never be more than a framework for the analysis of legal reasoning. Before concluding the paper, we will compare our approach to legal reasoning and hard cases to some other approaches from the literature. An appendix contains a semi-formal description of Dialogical Reason Based Logic.

\section{PURE PROCEDURAL LAW}

Our view of hard cases is based on a procedural view of legal arguments. Before expounding this view, we will discuss the main alternative to the purely procedural view of the law, the theory of law as institutional fact.

\subsection{Law as institutional fact}

The view that the legal conclusions for a concrete case are institutional facts that exist independent of their recognition by individual humans, is a popular modern variant of legal positivism. In fact, it is so popular that most lawyers which hold this view, are not even aware that they do so. (They do not even know what institutional facts are!)

The view of law as institutional fact comes approximately down to the following. The legal consequences for a case are the result of the case facts on the one hand, and the rules of law on the other hand. If the facts fulfil the conditions of one or more rules, these rules attach particular legal consequences to the case. The consequences are new facts about the case (e.g. that it is a case of negligence). These new facts are not natural or 'brute' facts; their existence depends on the rules that were applied to the case. They were, so to speak, 'constituted' by the rules. Borrowing terminology from Searle (1969), such rule-based facts are also called 'institutional facts'.

Institutional facts are only indirectly dependent on humans. The rules on which they are based are part of human culture, and as a consequence the facts that are based on them are part of, and dependent on, human culture too. But given a set of rules, the institutional facts do not depend on humans anymore. Whether some good is immutable, for instance, depends only on the nature of the good, and on the rules which define immutability. No human interference is necessary to make the good immutable.

Since in a legal positivist view the existence of rules is also a purely factual matter, the issue whether particular institutional facts obtain, depends completely and solely on the facts of the world. These are facts about the existence of rules on the one hand, and the facts of the case on the other hand. It is not necessary that the rules are explicitly applied, to obtain the institutional facts. The rules are, in a sense, self-applying. 
What does the view of law as institutional fact imply for legal reasoning? The aim of legal reasoning is to determine which institutional legal facts were constituted. These facts are independent of the argument that leads to them. However, humans do not have senses by means of which they can directly observe institutional facts. The only way to know the institutional facts, is to reconstruct, by means of the legal rules, the constitution of these facts out of the facts of the case. This reconstruction takes the form of a logical argument which uses the facts of the case and the rules as premises, and has the constituted institutional facts as its conclusion. The nature of the logic (e.g. whether it is monotonic or not) reflects the way in which rules constitute institutional facts. The parallel between constitution and derivation is depicted in the simplified Toulmin-structures of fig 1.

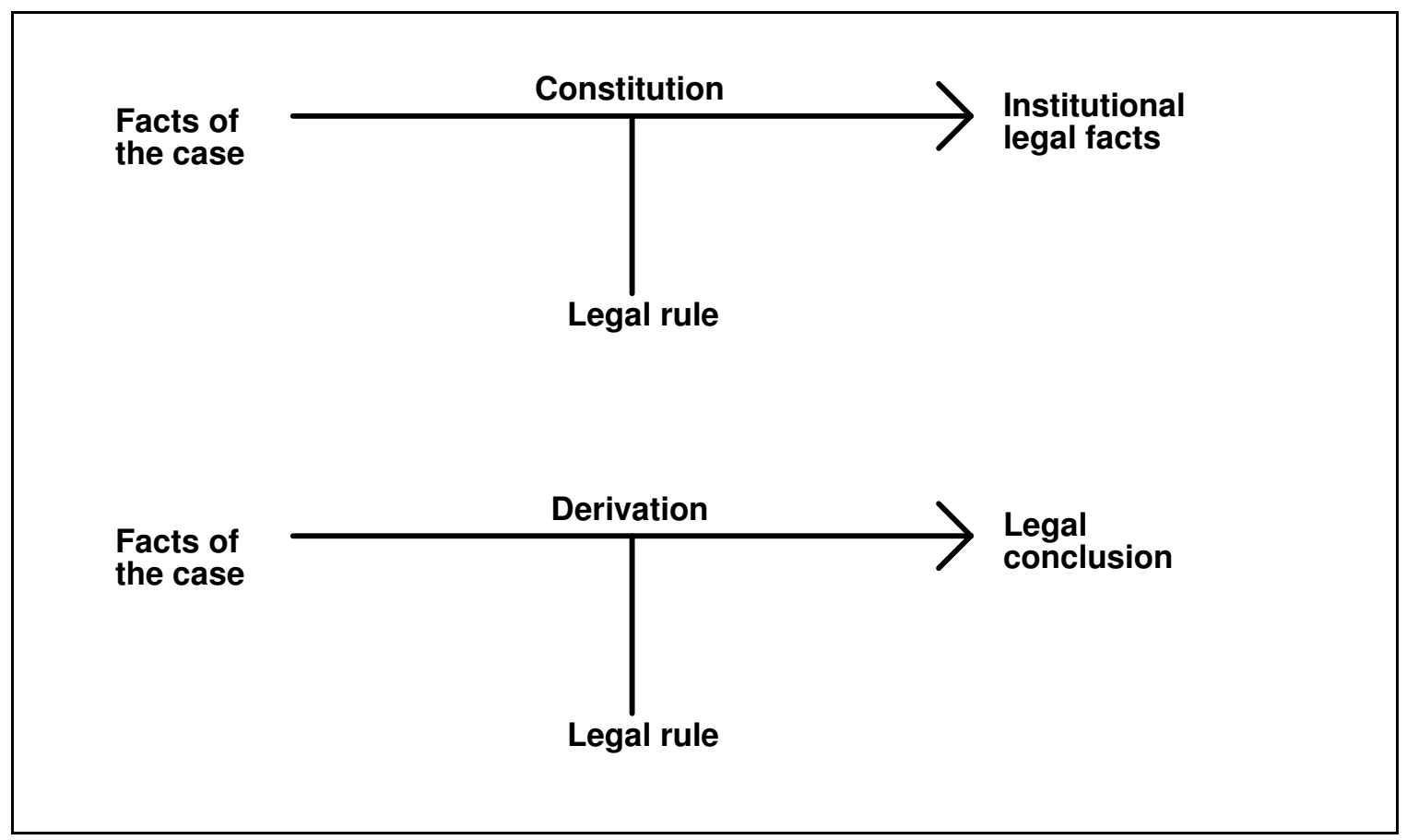

Figure 1: The reconstruction of constitution by means of derivation

\subsection{The open nature of legal arguments}

The view of law as institutional fact has both its advantages and its disadvantages. The disadvantages are easily summarised in the observation that legal arguments have an open nature. There is no set of rules and fact descriptions that are above dispute. Everything may be questioned, and logically there is no final answer to any legal question. Of course there are final answers, but they derive their final status from the procedure by which they are established. In the Netherlands there is no procedure to question the verdicts of the Dutch Supreme Court, and these verdicts are therefore final. But this does not mean that this same verdict, if given by some lower court, might not have been questioned.

What does it mean that everything can be questioned? Is there no foundation on which legal arguments can be based? Of course there is such a foundation; only it is not unshakeable. For most cases there will be a level on which the facts can be described, such that all involved parties do not question the description. Such a description may for instance include the fact that witness 
A says that he saw $\mathrm{X}$ open the car and drive away, while witness B says that $\mathrm{X}$ was watching a movie show at this same moment. In this case there will be no agreement about what $\mathrm{X}$ did, but there is agreement on the witness reports about what $\mathrm{X}$ did.

Similarly there will be agreement about the law on a particular level of description. For instance, most parties will agree that the statutes of a country contribute to the law, and they will also agree about the literal text of the statutes. However, they need not agree about the interpretation of the statute, nor about whether the statutory rule ought to be applied in this particular case.

It is important that the level on which the parties in a dispute will still agree, depends on the behaviour of the parties. There is no set of sentences about which the parties necessarily agree.

There are no hard facts, neither about the case, nor about the law. Theoretically it is even possible to dispute that statutes contain law, or that the officially published statutory texts are the real texts. (There might have been fraud with the publisher.)

Any legal argument that leads to a particular legal conclusion must be based on premises, but there are no premises which can be taken for granted. One always needs a procedure to establish the premises from which a legal argument can start. Most often such a procedure will have an expected outcome, but as our example of the clever lawyer illustrated, this need not be the case.

Does this imply that a party who refuses to accept any premise can block the drawing of all legal conclusions? No, because legal disputes are governed by both material and formal rules. The material rules indicate which legal rules are to be used by default. The formal rules (amongst others) indicate persons who can cut knots in the case that there are insoluble differences of opinion. However, neither the default rules, nor the decision makers provide the law with an unshakeable foundation. Default rules are there only by default, and the decision makers cannot build on an unshakeable foundation of legal knowledge either. In short, there are rules that guarantee that legal decision making processes are not arbitrary. These rules, however, do not guarantee that there is one fixed outcome for every legal case. The real outcome is determined by the execution of a procedure, and is not fixed as an institutional legal fact on the basis of unalterable facts and rules.

Does this mean that the theory of institutional legal facts is incorrect? The correctness of a description depends on the purpose for which the description is made. The view of law as institutional fact is incorrect if we are concerned with legal decision making in the case of conflicts, because it cannot account for the open ended nature of legal arguments. However, if we are concerned with the global description of legal systems, and we want, for instance, to explain the interlocking of material rules of law and power conferring rules, the view of law as institutional fact may be quite satisfactory ${ }^{3}$.

Since legal arguments and hard cases typically occur where legal conflicts are present, we prefer to adopt a procedural view of legal arguments ${ }^{4}$. The following sections elaborate this view.

3

4 legal knowledge system to simulate parts of the law for large scale purposes. In this connection one may think of detecting inconsistencies and modelling the social effects of legislation (Cf. Svensson 1992; Den Haan 1993; Kordelaar 1993). For these purposes, the view of law as institutional fact may be more satisfactory than the procedural view. 


\subsection{Pure procedural justice}

In practical affairs, we often adopt a particular procedure to obtain just results. In this connection we can distinguish between two cases. Either there is an independent standard to judge the outcome of the procedure, or there is no such standard. According to Rawls (1971, p. 85 f.), dividing a cake and a criminal trial are examples of the first case, gambling and elections are examples of the second case.

If three persons divide a cake, a good procedure would be to have one of them cut the cake in three pieces and let him choose a piece as the last person. Because of this procedure, he will normally try to divide the cake into three equal pieces, thereby conforming to the available independent standard, which says that each person is entitled to an equal piece of the cake. In such a case, Rawls speaks of perfect procedural justice, because the procedure more or less guarantees an outcome conform the pre-existing standard. The outcome of perfect procedural justice is substantive justice.

According to Rawls, in a criminal process there also is an pre-existing standard for the right outcome. If the defendant is guilty, he should be convicted, and otherwise not. A criminal procedure should be arranged in such a way that as many as possible guilty defendants are convicted and as many as possible innocent defendants are released. But there is no independent way to establish whether the procedure succeeds in its aims. Therefore, even if the procedure is made as just as possible, there is no guarantee that its outcome is substantially just. That is why a criminal procedure is an instance of imperfect procedural justice.

In the case of purely procedural justice, there is no independent standard to evaluate the outcome of the procedure. Instead, the only standard to judge the outcome is the course of the procedure. This is the case with elections, where the only way to evaluate the outcome is to investigate whether the elections were held according to a just procedure. (In this connection, Rawls uses the example of gambling.)

In our opinion, judging cases should be compared to elections and to gambling, rather than to dividing a cake or to a criminal procedure. The only way to arrive at the right outcome is to follow a legally correct procedure. There is no independent way to establish the correct outcome of a legal decision making process, even if we had perfect knowledge. Judging cases is an example of something perfectly procedural. But the outcome is in this case not justice, but law ${ }^{5}$. Why is law purely procedural? Because legal conclusions depend on the application of rules of law. The application of a rule is an actual event, and not a timeless logical step. It is not the case that in applying a rule of law we arrive at a conclusion which was already true independent of our drawing it. Legal 'reality' is constructed by applying legal rules, and it depends on what happens during the law applying procedure what will be the outcome of the procedure. Only by correctly applying the rules of law, we can arrive at valid legal conclusions, and these conclusions are valid because they are the result of correct application of the rules.

5 It may appear strange that judging cases should not be compared to a criminal procedure, which seems to be a paradigm of judging a case. To make this understandable, we must relate to the distinction between factual questions and legal questions. The criminal procedure, as meant by Rawls, concerns a factual question, namely whether the defendant is guilty. We are primarily concerned with legal questions, which assume that some factual questions have been answered 


\subsection{Law as a rhetorical procedure}

Not only is it the case that law is purely procedural, the nature of the procedure involved is rhetorical. By this we mean that the procedure has to do with convincing (one or more) other persons of some thesis. Convincing should in this context be interpreted as making somebody agree with a thesis by rational means, that is by adducing valid reasons which plead for the thesis ${ }^{6}$.

In an argument, one party tries to convince (or persuade) another party of the correctness of some thesis. The argument ends if both parties agree to the (denial) of the thesis, if they agree to disagree, or if the argument ends because of some institutional reason (e.g. time is over). With some qualifications because of the often institutionalised nature of legal arguments, this characterisation of arguments and how they end holds true for the law too. Each party tries to convince the other party and the judge of his position. They can do this by officially accepted and by non-accepted means (e.g. flirting with the judge). Ideally, only officially accepted means are used, or taken into account.

A procedure like this is a rhetorical procedure (Witteveen 1988). Characteristic for such a procedure is that there is no fixed outcome. By presenting reasons, each party tries to draw the outcome in his direction, but the final result cannot be determined logically. Even if some reasons logically should win (however this is defined), it is not guaranteed that they will win in fact. Moreover, if the procedure was followed correctly, there is nothing wrong in case logically 'compelling' arguments do not win. It is not the case that there is a right outcome which is better or worse approached by means of the legal procedure. There is no correct outcome for a legal case, other than the one arrived at by following the legal procedure in a correct manner. Therefore rhetorical legal procedures are purely procedural ${ }^{7}$.

\subsection{Rules of law as procedural rules}

Although the view that the legal consequences for particular cases are cognition-independent may be hard to defend, it still seems clear that the legal consequences of a case depend on pre-existing rules and the facts of the case, and not on the arbitrary will of the legal decision makers. As Hart has pointed out, legal decision making is not a matter of judge's discretion (Hart 1961, p. $138 \mathrm{f}$.) . It turns out, however, that the view of law as a rhetorical procedure can be combined with the recognition that legal decision makers are guided by rules of law. Rules of law can be seen as rules which specify how legal procedures are to be conducted. A procedure that violates a clearly applicable rule of law is not conducted properly. As a consequence the outcome of that procedure is not law, just as the outcome of wrongly conducted elections is invalid.

In theory it is imaginable that legal rules fully determine the outcome of a particular procedure. In that case, the procedure can lead to only one outcome, and the situation cannot be distinguished from the one in which legal rules establish independently existing institutional facts. Firstly, however, such a situation occurs less frequent than some might want us to believe. And, secondly, even if this situation would occur almost always, this would not remove the difference between pure procedural law and perfect procedural law; it would only make the difference more difficult to recognise.

6 Cf. the distinction between persuading and convincing, as made in Perelman and Olbrechts-Tyteca 1969.

7 Cf. Rorty 1980 in connection with the alleged procedural nature of all knowledge. 
To avoid possible misunderstandings, we want to point out that although material rules of law can be seen as procedural rules, they do not exhaust the rules that govern legal procedures. There are, for example, also rules that govern the burden of proof, that determine under which circumstances particular dialogue moves are allowed, and that conditionally disallow particular argument moves (think for instance of adducing illegally obtained evidence).

Another possible misunderstanding would be that if legal rules are dialogue rules, they are not capable of generating normal legal consequences such as obligations. Traditional rule application may be considered as a trivially simple interior dialogue. By means of such an interior dialogue, a legal subject may (non-authoritatively) establish the legal consequences of a particular case ${ }^{8}$.

\subsection{Hard cases}

The issue that matters in the present context, is that the outcome of legal procedures often is not determined by the rules governing these procedures. Although not all thinkable outcomes will be possible, a correctly conducted legal procedure often has more than one possible outcome. The actual outcome, that determines what is the law in this particular case, not only depends on the facts of the case and the rules of law, but also on the actual course of the procedure.

Not all cases that have more than one possible outcome, are hard cases. It will often happen that the parties involved in a procedure do not recognise the underdetermination of the procedure's outcome. The example at the beginning of this paper illustrates this situation. A mediocre lawyer may not recognise the possibilities of a case, and will overlook the chances of his client, or the defences of his opponent.

If the underdetermination is recognised, however, there is (at least) one stage in the procedure where one of the parties is forced in a direction which was not determined by the rules that guide the procedure. This is what we meant in the introduction with the sentence that in hard cases some a-rational decision making procedure is involved. For instance, if both parties in a legal conflict have different interpretations of a statutory passage, while no compelling reason was found (notice the procedural description) why one interpretation is to be preferred above the other one, a decision must be made regarding the correct interpretation. This decision obliges at least one party to take a direction in the procedure, namely to argue on the basis of this particular interpretation, which it did not want to go voluntarily, and which did not necessarily follow from the rules of the procedure. Cases that contain such underdetermined stages in their procedures are hard cases. Hard cases can be described as those in which at least one party is obliged to proceed in a manner that was not dictated by the rules of the procedure.

\section{CONSEQUENCES FOR LEGAL KNOWLEDGE SYSTEMS}

If the view of law as institutional fact were an adequate view of legal reasoning, legal knowledge systems might be built around theorem provers. The knowledge systems would take a set of legal rules (and other legal knowledge) on the one hand, and a case description on the other hand as premises, and would produce a logically derived conclusion as its output.

8 Van Haersolte 1975 offers an extended analysis of normative (legal) reasoning as interiorized dialogues. Cf. also Mead 1934, p. 335 about the self that 'arises in the development of the behaviour of the social form that is capable of taking the attitude of others involved in the same co-operative activity'. 
If the view of law as institutional fact is not considered to be an adequate view of legal reasoning, one should abandon the theorem prover approach and look for something different. What are the demands on legal knowledge systems which start from the procedural view of legal arguments? First it should model a procedure, rather than a logical relationship. A procedure differs from a derivation in that its course may be indeterminate. There are allowable and non-allowable moves, but characteristically the set of allowable moves makes more than one course of the procedure possible. And, more importantly, the different possible courses of the procedure may lead to different, incompatible results ${ }^{9}$. The set of possible dialogue outcomes will be inconsistent. Most procedures will, however, not allow that the actual outcome itself is inconsistent ${ }^{10}$. Each actual outcome will be a consistent subset of the set of all possible outcomes. We may conclude that $a$ legal knowledge system that takes the procedural approach seriously, should offer facilities for procedures with internally consistent, but mutually inconsistent outcomes.

The second demand derives from the open nature of legal arguments. The system should not work with a set of fixed premises (case facts and legal knowledge). Rather it should allow that in the course of the procedure extra information is added, and (possibly) that other information is retracted.

Procedures are governed by rules; not everything is allowed. Therefore a system that models procedures should contain procedure rules. It will turn out that the procedure rules are at least partly domain dependent. Therefore these rules should preferably be represented explicitly, rather than be built into the 'reasoning engine' of the knowledge system. Since domain knowledge can always be questioned, the system should also allow arguments about the procedural rules themselves.

A system that models procedures should not by itself determine the course of the procedures, unless the procedural rules only allow for one course. (Cf. a series of forced moves in chess.) To determine the actual course of the procedure, there must be some input from outside the system. This input will consist of moves in the procedure. The knowledge system must check this input to determine whether the proposed moves are valid ones.

If we take these demands together, we find that a legal knowledge system that starts from a procedural approach to legal arguments does not by itself draw legal conclusions ${ }^{11}$, but rather supports arguments conducted by external parties. The support that is offered consists of checks on the validity of argument moves and the determination of the winner of the argument.

9 The rules of derivation of a system of logic also allow of different proofs with different outcomes. The essential idea however is that all outcomes which can be proven, are logical consequences of the premises and as such consistent.

In the case of non-monotonic logics the latter need not be the case. There can be more than one extension of a theory (cf. Ginsberg 1987, p 11 f.). The construction of an extension can therefore be compared to a procedure. The derivability-relation for a non-monotonic logic, however, determines one particular set of sentences as derivable. In this way, the procedural nature of non-monotonic reasoning is abandoned again.

10 Since procedure rules are meant for human beings, the logical demands on the outcome of procedures can not be too severe. Humans have rather limited logical capabilities. Therefore, it cannot be expected from them that they completely avoid inconsistencies. The demand that the actual outcome of a procedure is consistent will therefore have to be loosened to the demand that the actual outcome is not clearly inconsistent. What counts as clearly inconsistent depends on the rules.

11 There is an exception if the dialogue rules allow for only one possible outcome. In that case this outcome can be computed by the system. 
Depending on the nature of the dialogue rules, there may be other kinds of assistance, such as the division of the burden of proof, and cutting knots if a dialogue gets stuck.

It is possible that a legal knowledge system is extended with a set of heuristic rules by means of which attractive argument moves can be computed. In that case, the knowledge system can also take over the role of one or more of the parties involved in an $\operatorname{argument}^{12}$.

In the following sections we propose Dialogical Reason Based Logic as the basis of a legal knowledge system that satisfies the above mentioned demands.

\section{REASON BASED LOGIC}

Hard cases are a phenomenon that lies at the heart of legal reasoning. They reflect both the open ended nature of the law, and the procedural nature of legal arguments. That makes hard cases an interesting touchstone for the adequacy of knowledge based systems as models of legal reasoning. If we want a computational model of legal reasoning by means of which hard cases can be identified, we need a language in which legal procedures can be described, and which makes it possible to decide whether the continuation of the procedure is dictated by reason or not. We propose to use Dialogical Reason Based Logic (DRBL) to provide us with a language to model legal procedures. DRBL is the dialogical version of Reason Based Logic (RBL), which is a normative theory about reasoning with rules and with reasons based on rules (Hage 1993).

\subsection{The essentials of Reason Based Logic}

$\mathrm{RBL}$ is characterised by the fact that it works with reasons pro and contra a conclusion. To draw a conclusion, one must collect the reasons which plead for and against it, and weigh them if necessary.

$\mathrm{RBL}$ treats rules as generators of reasons. If a rule is applied to a case, the facts that correspond to the conditions of the rule become a reason for the rule's conclusion. For instance, the facts that Peter took away the property of Alice on purpose, with the intention to appropriate it, correspond to the conditions of the rule that defines theft. As a consequence, application of this definition makes these facts into a reason why Peter is a thief. As already mentioned, this reason does by itself not guarantee the truth or derivability of the rule's conclusion; it may have to be weighed against other reasons.

The phenomenon of weighing reasons occurs on two levels. Not only are the conclusions of rules reasons that have to be weighed, that a rule must be applied to a case is itself also a conclusion that is the result of weighing reasons, namely reasons for and against rule application. The fact that weighing reasons occurs at two levels offers many possibilities to model the intricacies of reasoning with rules of law (cf. Hage 1993).

\subsection{The origin of reasons}

A reason consists of a set of (one or more) facts. A set of facts $\mathrm{S}$ forms a reason for $\mathrm{B}$, if and only if one ought prima facie to assume that $\mathrm{B}$, in the case that one believes the facts of $\mathrm{S}$. For instance, the fact that it has recently rained is a reason to assume that the streets are wet.

12 At the University of Limburg, the third author of this paper works on an intelligent legal tutoring system, where the computer plays the role of one of the parties in a legal dialogue. Cf. Hage et al. 1992. 
Therefore, if one believes that it has recently rained, one ought (prima facie) assume that the streets are wet.

As Hare (1963) has pointed out, reasons are 'universalizable'. If a fact of type A is a reason to believe a fact of type B, in general facts of type A are reasons to assume facts of type B. Thus, if one thinks that Jack ought to be punished because he is a thief, one should generally accept the fact that someone is a thief as a reason why that person ought to be punished.

Toulmin (1958) has described this phenomenon by pointing out that there are some kinds of rules underlying reasons, which he calls 'warrants'. These rules connect the reasons to their conclusions. Accepting a specific rule means accepting facts of the type mentioned in the rule conditions as reasons for the type of fact mentioned in the rule consequent. Both kinds of acceptance are the same. For instance, acceptance of the rule that one has the British nationality if one's parents have the British nationality means that one considers the fact that one's parents are British as a reason why one has the British nationality himself, and the other way round.

Accepting some fact(s) as a reason implies both accepting the facts as true, and accepting the validity of the underlying rule. Convincing someone by means of reasons involves adducing facts which are considered by that person to be reasons. In other words, one should adduce facts corresponding to the conditions of an accepted rule which has the desired conclusion.

Facts constitute a reason if they fulfil the conditions of an accepted rule. But sometimes a rule is applied analogously in which case facts which do not fulfil (all) the conditions of a rule are nevertheless a reason on the basis of that rule. On another occasion, an exception is made to a rule, and facts that fulfil the rule conditions are not considered to be reasons.

Without further argument, the facts that fulfil the conditions of a rule, and only these facts, are made into a reason by that rule. But it is possible to adduce reasons why a rule should be applied, although its conditions are not fulfilled. It is also possible to adduce reasons why an exception should be made, and a rule should not be applied although its conditions are fulfilled ${ }^{13} 14$.

Following terminology introduced by Raz (1975), reasons that exclude the application of a rule are called 'exclusionary reasons'. Just like other reasons, exclusionary reasons are based on underlying rules (e.g. on the rule that one should not apply the normal rules of inheritance to the murderer of the testator).

Where legal solutions for cases are involved, applicable rules of law generate not only reasons for the solution of the case, but also reasons that exclude the application of non-legal rules to the same case. E.g., a legal definition of default defines which facts count as reasons to assume default, and excludes the application of all non-legal reasons that define default ${ }^{15}$. Exclusionary reasons are an instrument employed by the law to let rules of law prevail over non-legal rules, as far as the legal solution of a case is concerned.

13 The way in which RBL deals with exceptions is similar to the way in which they are dealt with in Pollock 1987.

14 The phenomenon that an exception is made to a rule is illustrated by the famous case Riggs v. Palmer, where the rule that inheritance will be settled according to the last will of the testator is not applied, in order to exclude inheritance by the murderer of the testator. The fact that someone murdered the testator is a reason why the normal rule about inheritance should not be applied to him.

15 Sometimes not all non-legal rules are excluded. In particular those rules that were not taken into account when formulating the legal rule, are not excluded. A satisfactory discussion of this topic would, however, exceed the boundaries of this paper. Cf. Hage 1992. 


\subsection{Weighing reasons}

Application of a rule constitutes a reason for the rule's conclusion. If there are both reasons for and against a particular conclusion, the reasons must be 'weighed' against each other. It is not easy to imagine what weighing reasons amounts to. Reasons do not come labelled with a weight, and people are usually not capable of specifying the weight of a reason. They do not even know the scale on which the weight of a reason is measured. Nevertheless, 'weighing reasons' is a common expression, and people are sometimes aware of a psychological process which might be described as the weighing of reasons.

In our opinion, reasons do not have an absolute weight, but in some cases it is possible to attribute relative weights to reasons. In these cases the question which reason is more important can itself be argued on the basis of reasons (cf. Ashley and Rissland 1988).

For instance, assume that a judge must decide whether a supermarket is allowed to dismiss an employee. The supermarket has two employees and it is established that it needs to dismiss one of the two employees for financial reasons. One of the employees is slightly more capable for the job; the other one has been in service for a longer period of time.

For each of the two employees there is a reason why (s)he should be dismissed and a reason why (s)he should not be dismissed (but rather the other employee). The judge has to weigh these reasons. In making his decision, he can use the additional reason that the greater capability of one employee should not count for very much, since the other employee is good enough for the job. By using this weighing-reason, the judge can decide that the longer employment outweighs the greater capability, and that the person with the shortest term of employment should be dismissed. Another way to establish the relative weight of reasons is by means of case-based reasoning. The techniques of case-based reasoning as described by, for instance, Ashley (1991), can be interpreted as means to establish the relative weight of reasons. In this interpretation, dimensions of cases represent reasons derived from these cases (Hage 1993).

\section{THE DIALOGICAL VERSION OF REASON BASED LOGIC}

The process of adducing reasons pro and contra can be considered with the question in mind, to what conclusion a purely rational being would come if he started from a fixed number of premises. From this perspective, every available reason should be taken into account, and the determination of the outcome is along the line of traditional logical proofs. By this we mean that an argument starts with the set of premises and leads to the conclusion by means of a number of allowed steps. The RBL-theory that uses this approach is called Monological Reason Based Logic (Hage 1993).

The process of adducing reasons for and against conclusions can also be approached as a dialogue (debate) between two or more persons. The parties in the dialogue adduce arguments to convince the other parties of their position. If each party in such a dialogue is fully rational, in the sense that he adduces the best possible reasons for his own position, and the best possible reasons against the position of his opponent, the outcome of the discussion would be the same as in the case that the conclusion of the argument would have been derived according to Monological Reason Based Logic ${ }^{16}$.

16 At least, it is possible to develop dialogical logics that exhibit the property that fully rationally conducted dialogues lead to the same outcome as some form of established monological logic. In these cases, it may be said 
It is, however, interesting to consider the (more realistic) possibility that the parties in the discussion do not always start from a fixed set of premises and do not always follow the strongest possible strategy. For legal purposes, this perspective on arguments is the more attractive one, especially if we consider the law as the outcome of a rhetorical procedure. In connection with legal reasoning the procedural perspective has been defended by Alexy (1978) and it has been given a computational elaboration by Gordon (1993a and 1993b). Dialogical Reason Based Logic is a variant of RBL which takes open ended dialogues as the starting point for the description and evaluation of (legal) arguments.

DRBL is a procedural logic. Next to the obvious difference that a procedural logic uses argument moves, where a monological logic uses derivation steps, there are other fundamental differences between monological and procedural logics. A difference which is very important for our purposes, is that procedural logics work 'top down'17. A procedure starts with the positing of a thesis, and if the thesis is questioned, it will be defended. In a monological logic, the conclusion forms the end of a chain of reasoning steps which begins with the premises. An argumentation procedure starts with the conclusion and develops toward the ultimate propositions on which the thesis is based. As a consequence, the 'premises' of a dialogue can be introduced in the course of the dialogue. At the start of the dialogue, the premises are not yet given, and it depends on the actual course of the dialogue (which defence is actually given and accepted for the thesis), on which premises the thesis will ultimately be based.

In this paper we will outline the framework presented by DRBL as a means for analysing the nature of hard cases. We only speak of a framework, because a full version of DRBL includes a set of dialogue rules. We have already mentioned that dialogue rules are part of the domain that is being modelled. As a consequence, it does not make much sense to make the dialogue rules of a particular domain, part of the logic. That is why we restrict ourselves to a framework of DRBL, that must still be filled in with domain dependent dialogue rules. The appendix contains a number of relevant definitions and an example of dialogue rules for a variant of DRBL in which there are two parties and an arbiter involved in a dialogue.

\subsection{Elements of two person-dialogues}

We consider legal disputes to be dialogue games between two parties ${ }^{18}$ about a specific proposition, which is called the thesis of the dialogue game. One party, the proponent, claims and defends the thesis, the other party, the opponent, does not accept and maybe even denies the thesis. Both parties are allowed to make argument moves ${ }^{19}$, such as adducing reasons and asking for justifications. In a dialogue each party seeks to make moves, such that the other party is

that axiom-based monological logics and dialogical logics are 'different garbs' for the same thing Cf. Barth and Krabbe 1982, p. 3f., and Lorenzen and Lorenz 1978.

17 A procedural logic need not work top down by definition. It is possible to start with a discussion of theses which in the end turn out to have had the function of 'premises' for a later part of the discussion. It is, however, common to take a top down approach to arguments which are considered in a procedural manner.

18 The assumption that a legal debate is between two persons is only made for the ease of exposition. As we will see in section 1., and will be illustrated by our example of the post traumatic neurosis case, it may be fruitful to treat legal debates as a many-party debate.

19 Argument moves in our sense of the word resemble more the type of argument moves as discussed by Gordon (1991, 1993a, 1993b), than the argument moves as discussed by Skalak and Rissland (Rissland and Skalak 1991; Skalak and Rissland 1992). 
committed to the first party's point of view. Moreover, they also try to avoid to become committed to their opponent's point of view themselves. The dialogue is the process of making argument moves which in the end leads to some result concerning the thesis.

A dialogue game is a set of one or more dialogues. There is one top-level dialogue, which is about the thesis of the dialogue game. The top-level dialogue, and also other dialogues, often contain sub-dialogues, the thesis of which is a claim in the dialogue one level higher. The rules for the top-level dialogue also govern the sub-dialogues. The structure of dialogues is tree-like. Some moves in a dialogue commit the party which makes them to accepting particular sentences. A dialogue about a particular thesis ends when the opponent has accepted the thesis, or when the proponent has withdrawn it.

A commitment store is a set of sentences to which a party is committed. Since both parties are committed to the sentences in their own set (which contains at least a set of dialogue rules), each dialogue game counts at least two commitment stores.

For legal dialogues, we also want to make use of the function of an arbiter. We will see that sometimes there are no rational means to determine the outcome of a dialogue. In such cases, a party can invoke the arbiter, to make the continuation of the dialogue possible. For instance, if there is a difference of opinion about the validity of a particular rule, which cannot be solved rationally, it is necessary to cut the knot. In such a case, the arbiter must make a decision about the validity of the rule, on the basis of which the dialogue can continue.

\subsection{Argument moves}

As mentioned before, in a discussion both parties will try to adduce reasons for their positions and against their opponent's position. In this section we pay attention to the several possible argument moves. It should, however, be noted that such a presentation necessarily involves the presupposition of debating rules. The framework of DRBL itself however does not commit to specific debating rules. Moreover, it even allows discussions about some dialogue rules ${ }^{20}$. This means that the following presentation about the process of reasoning is subject to changes at a number of points.

\section{$\underline{\text { CLAIMS }}$}

A dialogue game comes into existence when a party claims some sentence. For instance, a party (A) claims that the other party (B) owes him ten thousand dollars. By making a claim, one starts a dialogue with the claimed sentence as its thesis. The party who made the claim becomes the proponent in this dialogue. Since a dialogue game may contain more than one dialogue, it is possible that the party who is the proponent in one dialogue, is the opponent in another dialogue within the same dialogue game.

\section{ACCEPTANCE}

In principle, the opponent has four ways to react to a claim. The claim can be accepted, it can be questioned, it can be denied, and it can be refused. If a claim is accepted, the dialogue which was started by the claim immediately ends. Both parties are committed to the claimed sentence.

20 Because discussions about the rules of a dialogue presuppose rules themselves, it is not possible to draw all rules of a dialogue into the discussion. 


\section{QUESTIONING}

If a claim is questioned, the proponent has the choice between withdrawing the claim and defending it by giving reasons in the form of further claims ${ }^{21}$. For instance, the claim that B owes A ten thousand dollars is defended by the further claim that the fact that B borrowed the money from A is a reason why B ought to pay A ten thousand dollars. This new claim starts a subdialogue about the thesis that the fact that $\mathrm{B}$ borrowed ten thousand dollars from $\mathrm{A}$ is a reason why B ought to pay A ten thousand dollars.

\section{DENIAL}

Denial is not an independent type of argument move. In fact, it is just another claim, namely a claim of the negation of the previous claim's sentence. In our example, it would be the claim that B does not owe A ten thousand dollars. By making this claim, a sub-dialogue is started about the negated sentence ${ }^{22}$. The outcome of this sub-dialogue determines to a large extent the outcome of the dialogue from which it started. For instance, if B wins the dialogue with the thesis that he does not owe the money to A, this implies that A lost the dialogue about the thesis that B owes the money.

\section{REFUSAL}

The refusal of a claim comes down to making a claim that the previous claim was not allowed. In a criminal trial, for instance, it is (at least in the Netherlands) not allowed to adduce evidence that was obtained illegally. A party who adduces evidence needs not prove that this evidence was obtained legally; the opponent must prove that it was obtained illegally. In dialogues, this can be accomplished by the refusal of a claim. If, for instance, A has contracted with B that he would not sue $B$ to repay the loan, B can refuse A's claim that the loan from A to B is the reason why B ought to pay ten thousand dollars.

As mentioned, refusal takes place in the form of a counterclaim. The opponent of the main dialogue becomes proponent in a sub-dialogue about the thesis that the former proponent was not allowed to make his claim. If this counterclaim holds, the wrongly made claim must be withdrawn.

Refusing a claim is an example of a discussion about the rules of the dialogue. There are rules that determine under which circumstances a party is allowed to make a claim. The refusal of a claim implicitly questions either the validity of one of these rules, or it questions the application of such a rule to a case where the conditions of the rule are fulfilled. In general, refusing an argument move involves a discussion about the rules which define valid argument moves. In section 5.6. we will give more details on how a refusal starts a dialogue about the dialogue rules.

\subsection{Defending a reason}

If a claim is questioned, and the claiming party does not want to retract it (yet), the claiming party must adduce one or more reasons for the claim. Such a reason consists of the statement that one or more facts together are a reason for the questioned claim. For instance, A might adduce that the

21 A call to the arbiter is also possible. These calls will be discussed in section 1.

22 A party whose claim is denied is allowed to treat the situation as if his claim was only questioned. The reason for this is that otherwise the denying party can draw the initiative in the dialogue to himself. That would make it possible to frustrate a winning strategy. 
fact that B borrowed ten thousand dollars from him is a reason why B ought to pay him ten thousand dollar. B can accept this further claim, but if he questions it, A must commit B to the thesis that there is a particular rule which applies to the present case. Only in this way is it possible to commit one's opponent to the thesis that particular facts are a reason for one's earlier thesis.

To commit the opponent to the sentence that particular facts are a reason for a thesis, the proponent must commit the opponent to the sentence that the rule which makes these facts into a reason applies in this particular case. In our example, A should commit B to: 'The rule which states that who borrows an amount of money, owes the money to the person it was borrowed from, applies to this particular case.'

This sentence, although it is about a rule, is a sentence like any other one, and can be argued for by adducing reasons for it. Therefore, the same procedure applies as for any other reason. In this connection, the fact that a rule is applicable counts as a reason why the rule applies. Notice the difference between the sentence that a rule is applicable on the one hand, and the sentence that a rule (actually) applies on the other hand. The former is a reason for the latter, while the latter constitutes a reason for the rule's conclusion.

To commit the opponent to the sentence that a rule is applicable, the proponent must commit him to the validity of the rule, and to the facts that fulfil the rule's conditions. In our example, the opponent must be committed to the sentence that he borrowed ten thousand dollars from A, and to the sentence that the rule is valid, which states that who borrows an amount of money, owes the money to the person it was borrowed from.

If the opponent is committed to the validity of a rule and to the facts that fulfil the rule's conditions, he is committed to the applicability of the rule, unless he commits the proponent to the sentence that the rule is excluded.

This corresponds to a shift in the burden of proof. If the facts that fulfil a rule's conditions and the rule's validity are established, the rule is by default applicable. If the opponent thinks that the rule is nevertheless not applicable, he has the burden to prove that the rule is excluded. If he does not succeed in this proof, he becomes committed to the applicability of the rule.

The sentence that a particular rule is excluded is just another sentence that can be argued for by adducing reasons. Such reasons are generated by what might be called meta-rules. Examples of such meta-rules are Lex Specialis, Lex Superior, and Lex Posterior. There are more specific metarules, such as the rule that in the case of rent of business accommodations, the normal rules for rent are not applicable. This latter rule makes the fact that in a case rent of business accommodations is concerned, into a reason against applicability (and consequently for exclusion) of the normal rules for rent. 


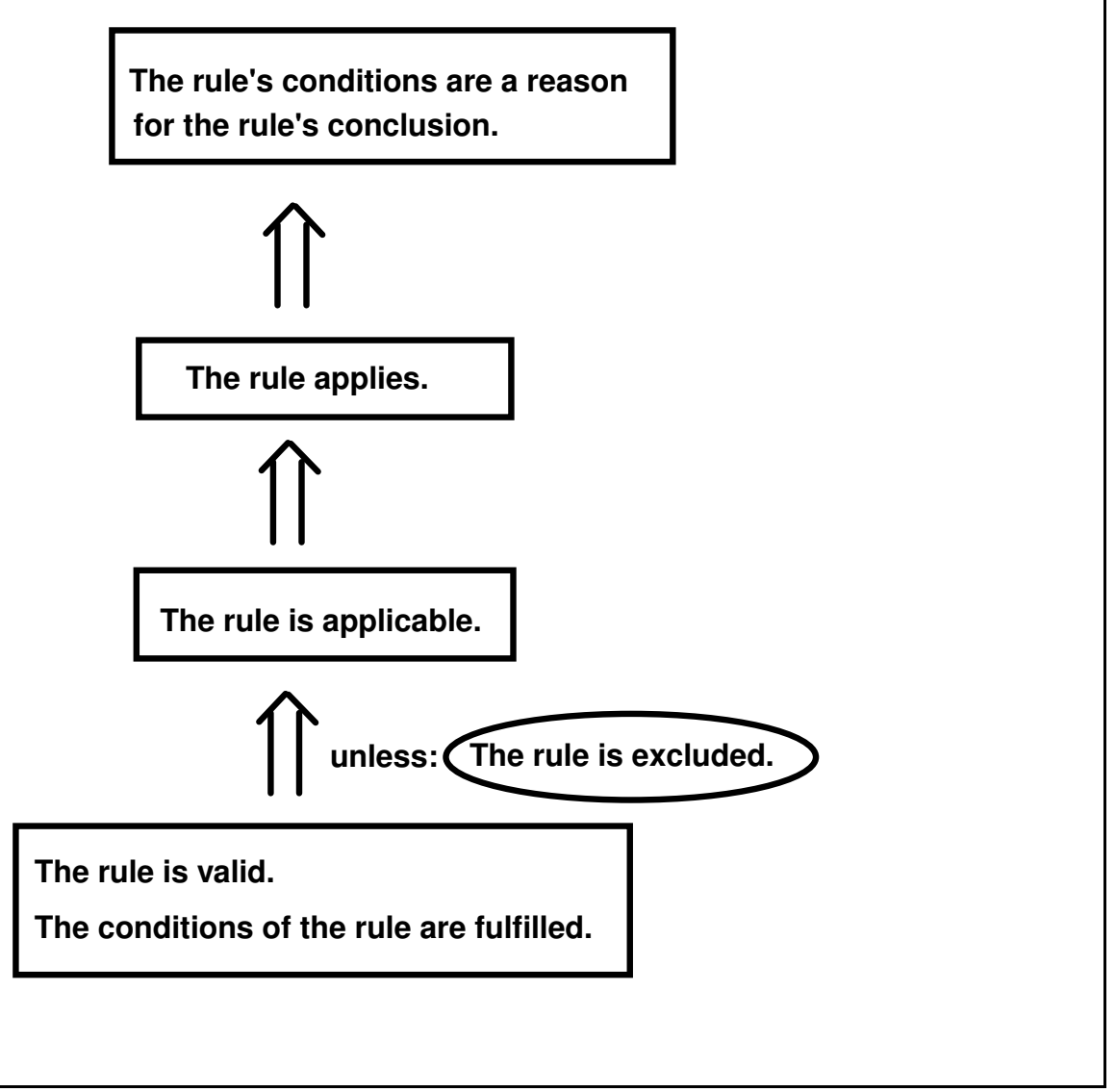

\section{Figure 2: The steps that lead to the constitution of a reason.}

Figure 2 illustrates the steps from basic facts such as the validity of the rule and the facts that fulfil the rule's conditions to the constitution of a reason for the rule's conclusion. The first step that leads to the applicability of the rule is a semi-hard one. It can only be defeated by the fact that the rule is excluded. There is no weighing of reasons involved. The step from the applicability to the application of a rule is soft: The fact that a rule is applicable is only a reason for the application of the rule, which may have to be weighed against reasons which plead against application. (An example of such a reason would be that application is against the rule's purpose.) The final step, from the application of a rule to the constitution of a reason for the rule's conclusion, is hard. If the rule actually applies, the facts that correspond to the rule conditions (or the facts which make the rule applicable by analogy) become a reason for the rule's conclusion.

\subsection{Weighing reasons}

If the proponent has adduced one or more reasons for the thesis, he can claim that the adduced reasons outweigh the reasons against the thesis. This is what we call an abstract weight-claim, because this claim refers to the reasons for and against the thesis without mentioning them.

If the opponent accepts this claim, he becomes committed to the thesis of the dialogue. If he does not want to accept the thesis, two lines of attack are open to him. He can adduce reasons against the thesis, or he can question or even deny the abstract weight-claim.

If the opponent wants to adduce reasons against the thesis, he must follow a similar procedure as the proponent had to follow to adduce reasons for the thesis. That is, he must claim that particular 
facts are reasons against the thesis. These claims start sub-dialogues in which the former opponent is the proponent, and vice versa. At the end of these sub-dialogues, the set of reasons for and against the thesis may have changed. The original proponent now has the choice between adducing extra reasons which plead for the thesis, or (abstractly) reclaim that the reasons for the thesis outweigh the reasons against it.

The process of adducing reasons may be repeated as long as the parties want to. In the end the proponent of the thesis must commit the opponent to the sentence that the reasons for the thesis outweigh the reasons against it. The procedure for this is the normal one of committing someone to a sentence. That is, if the opponent does not accept that the reasons pro outweigh the reasons con, he can question, or even deny the claim, with the normal consequences.

If an abstract weight-claim is questioned, it can be defended by adducing a concrete weight-claim that says that the reasons for and against the thesis, that have been accepted in the dialogue, lead to the thesis. This is a concrete weight-claim, because it literally mentions the reasons involved. Concrete weight-claims are sentences like any other, that can be argued for by means of reasons. A precedent can for instance function as a reason why a particular concrete weight-claim is true (Hage 1993).

Figure 3 illustrates the process of alternatingly adducing reasons for and against a thesis and the end of this process in the form of the claim that the reasons for the thesis outweigh the reasons against. The thin boxes indicate that these reasons need not to be adduced before the claim is made that the reasons for the thesis outweigh the reasons against it.

\subsection{Commitment}

Commitment plays an essential role in dialogues. The very purpose of a dialogue is to commit one's opponent to a sentence. Commitment to a sentence also has consequences for the dialogue moves one can make.

In general, a dialogue party is committed to the sentences in his own commitment store. A sentence is added to a party's commitment store if this party either claims this sentence, or accepts it. If a party withdraws a sentence, the sentence is removed from his commitment store. (It goes without saying that a party is not always allowed to withdraw sentences.)

If a party accepts that the reasons for a thesis outweigh the reasons against this thesis - that is, if he accepts an abstract weight-claim - he must also accept the thesis itself. This case of forced acceptance is the basic mechanism in DRBL, by means of which a party can be committed to a thesis.

There are some other cases of forced acceptance. If a party accepts that a rule applies, he must also accept that the facts corresponding to the rule conditions are a reason for the conclusion of the rule. Moreover, if a party has accepted that a rule is valid and that the facts corresponding to the rule conditions are the case (true), he must also accept that the rule is applicable, unless he claims that the rule is excluded. If he withdraws the claim that the rule is excluded, he must still accept that the rule is applicable. If a party is committed to the applicability of a rule, he is also committed to the thesis that the applicability of this rule is a reason to apply the rule. 


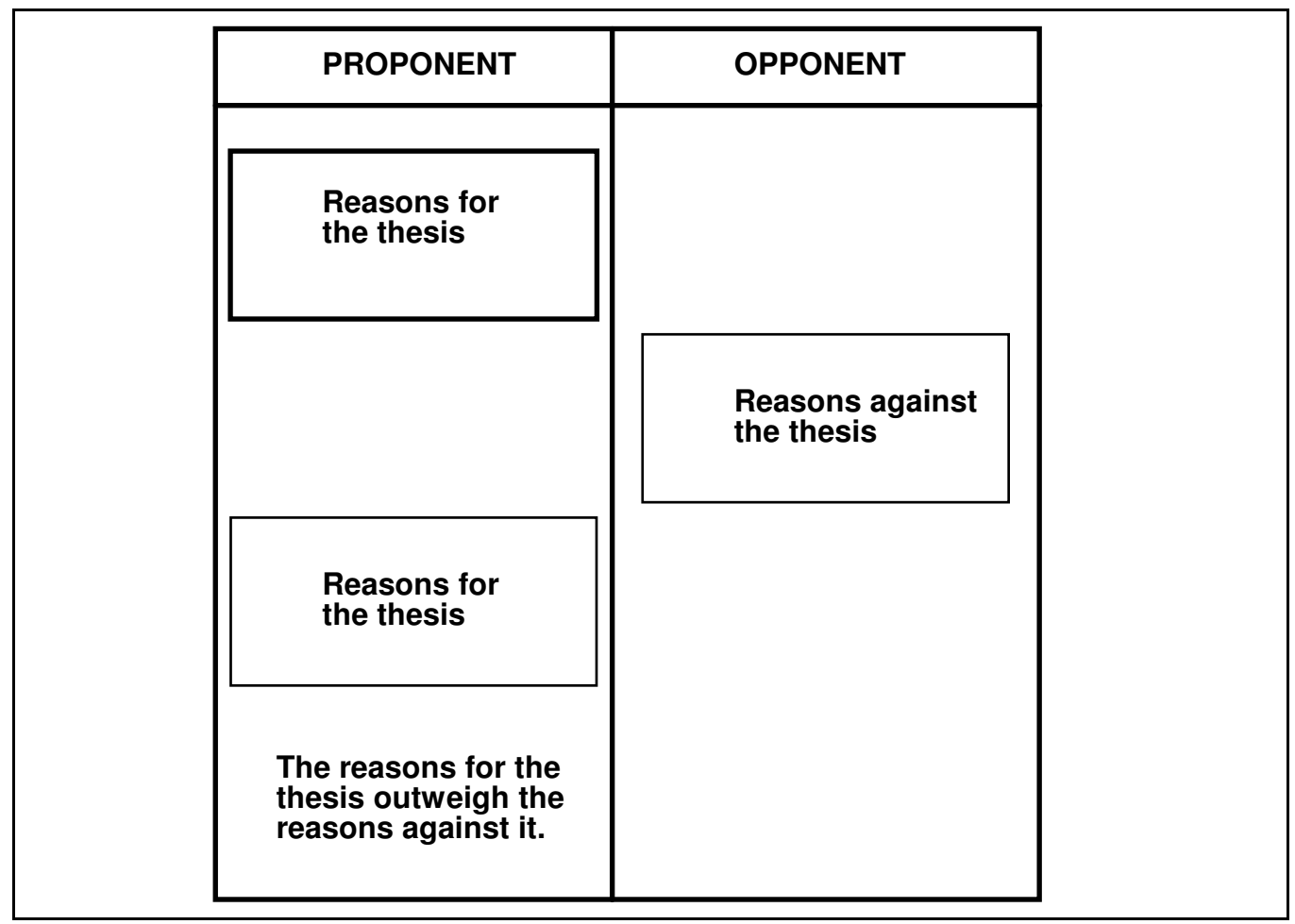

Figure 3: Weighing reasons.

If a party is forced to accept a sentence which he is not allowed to accept because of a prior commitment, he must first withdraw the sentence that prevents the acceptance. Forced acceptance sometimes brings forced withdrawal with it.

\subsection{Discussion about dialogue rules}

In DRBL, dialogue rules have the same form as all other rules. They indicate under which circumstances dialogue moves of a particular type are possible. For this purpose, dialogue moves are considered as logical individuals that can have the property of being possible ${ }^{23}$.

Making an argument move presupposes that this move is possible. The possibility of an argument move can be assumed if the conditions of a valid dialogue rule, that allows this move, are fulfilled. Refusing a move comes down to the claim that this move is not possible. The party who refuses an argument move has the burden to prove that the move was not possible.

23 A dialogue rule that allows the questioning of a just made claim would look as follows:

$\operatorname{valid}\left(\operatorname{rule}\left(100,\left(\operatorname{argument} \_\operatorname{move}(N, P)=\operatorname{claim}: S\right) \& \sim \operatorname{committed}(O, S) \Rightarrow\right.\right.$

$\mathrm{P}(\operatorname{argument}$ move $(N+1, O)=$ question: $S)))$

This dialogue rule has number 100 as its identifier. Its first condition is that argument move number $\mathrm{N}$, made by $\mathrm{P}$, is the claim that $\mathrm{S}$, where $\mathrm{S}$ is a sentence. Its second condition is that party $\mathrm{O}$ is not committed to $\mathrm{S}$. If these conditions are fulfilled, the facts that fulfil the conditions will normally be a reason why it is possible (the Poperator) that the next move $(\mathrm{N}+1)$ of party $\mathrm{O}$ consists of the questioning of $\mathrm{S}$.

Notice that the rule is not stated independently, but rather as a logical individual in a statement that the rule is valid. 
There are four ways to do so. First it can be argued that the rule is invalid ${ }^{24}$. To that purpose it must be shown that the reasons against the validity of the rule outweigh the reasons for the validity.

Second, one may argue that the dialogue rule is excluded in this particular case. This would, for example, be possible in the case of a claim of illegally obtained evidence. For this purpose there should be a dialogue rule that says that the rule that allows claims about a sentence $S$ is excluded if $\mathrm{S}$ contains illegally obtained evidence.

Third, it may at least theoretically be argued that a dialogue rule should not be applied, although it is applicable, because there are outweighing reasons against applying the dialogue rule. Until now, we know of no convincing examples of this theoretical possibility.

Finally it is possible to argue that, although a dialogue rule provides a reason why an argument move is possible, there are nevertheless outweighing reasons why the move is impossible. We know of no convincing examples of this theoretical possibility either.

The reader should notice that the four mentioned possibilities that a dialogue rule does not lead to its normal result, are exactly identical to the situations where 'normal' applicable rules do not lead to their conclusions. The reasoning about dialogue rules is identical to the reasoning about any other kind of rule. Reasoning about dialogue rules is just reasoning in the framework of DRBL.

\subsection{Winning strategies}

Sometimes a dialogue party has a strategy at his disposal that, in the end, forces his opponent to accept a particular thesis. Take the case where the commitment stores of the parties A and B both contain the following two sentences ${ }^{25}$ :

valid(rule (13, thief $(x) \Rightarrow$ punishable $(x))$ )

thief (John)

In this case, each party has a winning strategy to commit the other party to the sentence punishable (John).

The strategy consists of adducing that the fact that John is a thief as a reason why John is punishable. This reason-statement can be defended by pointing out that the rule that thieves are punishable is valid (both parties are committed to that) and that the condition of the rule is fulfilled (both parties are committed to John's being a thief). As a consequence, both parties are committed to the thesis that the rule about the punishability of thieves applies, and that makes the circle round.

The availability of a winning strategy for a thesis does not mean that the party which has such a strategy will actually win the dialogue about this thesis. The strategy must actually be executed in order to win the dialogue. Suppose, for instance, that the opponent adduces that the fact that John is a minor is a reason why application of the rule is excluded. The proponent is not committed to the minority of John, nor to the rule which makes this fact into a reason to exclude the original rule. Yet, he may accept the exclusionary reason adduced by the opponent. If he does, the outcome of the dialogue will not be that John is punishable. After such an admission, the winning

24 The invalidity of the rule, just as the other possibilities that are discussed, does by itself not lead to the conclusion that a move is impossible. To arrive at that conclusion, we need the background rule that a dialogue move is impossible unless it is explicitly made possible by some rule.

25 And no other statements, except about the validity of dialogue rules. 
strategy will moreover be made impossible. From this we can see that the availability of a winning strategy only means that, if the proponent makes the right argument moves, the opponent must in the end accept the conclusions, no matter how he defends himself.

The notion of a winning strategy is in an essential respect different from the notion of winning a dialogue. Winning a dialogue has to do with the outcome of an actually conducted dialogue. The winning is an event that actually occurred. The availability of a winning strategy, on the other hand, is the result of the contents of a number of commitment stores. The availability of a winning strategy for a particular thesis resembles the possibility to derive this thesis in a monological logic (Cf. Lorenzen and Lorenz 1978, p. 12). In fact, there is a winning strategy for a thesis if this thesis can according to Monological Reason Based Logic be derived from the sentences to which the opponent is committed ${ }^{26}$. The notion of a winning strategy is, in short, non-procedural. This will turn out to be important for our characterisation of hard cases.

\subsection{Deadlocks and the role of the arbiter}

A dialogue about a sentence ends if the sentence is either accepted by the opponent in this dialogue, or if the proponent of the dialogue withdraws the sentence. Although there are some cases in which a party in a dialogue can be forced to accept or withdraw a sentence, there are also situations in which this is not the case. This can lead to deadlocks in the dialogue, in particular if the opponent of a claimed sentence is not forced to withdraw the sentence, while the opponent is not forced to accept it. The claim of this sentence remains open, and if the sentence is relevant for the outcome of the dialogue game as a whole, the main claim of the dialogue can remain open too. The dialogue game would not end.

We have chosen to introduce the function of an arbiter to deal with deadlock situations. The arbiter gives decisions if the dialogue gets stuck. These decisions lead to commitments on the basis of which the dialogue can continue.

If the arbiter is called upon, he must decide about the questioned claim. If the arbiter decides about a sentence, this sentence or its denial is added to the commitment stores of both parties. The party who invoked the arbiter remains in turn to move.

The invocation of the arbiter is itself a kind of claim ('The arbiter must decide this issue') which can be refused by the other party. If this refusal is questioned, the refusing party must defend the denial of the claim for which the arbiter was invoked. If this defence succeeds, that is, if his opponent accepts the negated sentence, the invocation of the arbiter must be withdrawn.

In DRBL the arbiter cuts a knot when called upon by a party in the dialogue game. Under what circumstances is a party allowed to invoke the arbiter? We propose that a party can invoke the arbiter if a claim of his has been questioned. Moreover, a party may not invoke the arbiter to decide about a particular claim if there is a rational solution available with regard to the contents of the claim. In section 6.3. we will discuss the notion of a rational solution at length. In anticipation of that discussion, we preliminary define the availability of a rational solution as the presence of a winning strategy.

26 The truth of this sentence depends on the precise rules given for dialogues. There are some phenomena in DRBL, such as the refusal of a claim, that are not incorporated in MRBL. These phenomena should be left out DRBL to guarantee the close correspondence between derivability in MRBL and the availability of a winning strategy in DRBL. All of this does, however, not subtract from the main idea that the availability of a winning strategy in DRBL and the possibility of proof in MRBL are closely connected. 
The rule that the arbiter can only be invoked for a claim for which no winning strategy exists, is inspired by the consideration that a party should not be able to make every case into a hard one. A case becomes hard when the arbiter is invoked. There are clear cases, and the dialogue rules should not allow to turn these cases into hard ones. How the clear cases are to be distinguished from hard ones is a question that has preliminary been answered by invoking the notion of a winning strategy. To what extent this answer is satisfactory, is the issue for the following sections.

\subsection{An example of a hard case in the dialogical approach}

The discussion of the role of the arbiter in DRBL has made it possible to define hard cases more precisely: A case is hard if, in the dialogue about the case, the arbiter actually decides about a sentence. To illustrate how our dialogical model of legal reasoning enables us to identify hard cases, we will work out an example.

Suppose that A and B argue about the question whether B owes A ten thousand dollars (our old example). The following table contains a schematised versions of a possible dialogue between A and $\mathrm{B}$.

\begin{tabular}{|c|c|l|c|l|l|}
\hline \multicolumn{6}{|l}{ THE COMMITMENT STORES OF A AND B } \\
valid(rule(1, borrowed_from $(x, y$, amount $) \Rightarrow$ owes $(x, \mathrm{y}$, amount $)))$ \\
borrowed_from(B, A, \$10,000)
\end{tabular}




\begin{tabular}{|c|c|c|c|c|c|}
\hline 15 & $\begin{array}{l}\text { Ques- } \\
\text { tion }\end{array}$ & $\begin{array}{l}\text { applicable(rule }(2, \text { loan_more- } \\
\text { than-thirty-years-old } \Rightarrow \\
\text { excluded(rule }(1, \\
\text { borrowed_from }(x, y, \text { amount }) \\
\Rightarrow \text { owes }(x, y, \text { amount })))\end{array}$ & 16 & Claim & $\begin{array}{l}\text { valid(rule }(2, \text { loan_more-than- } \\
\text { thirty-years-old } \Rightarrow \\
\text { excluded(rule }(1, \\
\text { borrowed_from }(x, y, \text { amount }) \\
\Rightarrow \text { owes }(x, y, \text { amount })))\end{array}$ \\
\hline 17 & $\begin{array}{l}\text { Ques- } \\
\text { tion }\end{array}$ & $\begin{array}{l}\text { valid(rule }(2, \text { loan_more-than- } \\
\text { thirty-years-old } \Rightarrow \\
\text { excluded(rule }(1, \\
\text { borrowed_from }(x, y, \text { amount }) \\
\Rightarrow \text { owes }(x, y, \text { amount })))\end{array}$ & 18 & Arbiter & $\begin{array}{l}\text { valid(rule }(2, \text { loan_more-than- } \\
\text { thirty-years-old } \Rightarrow \\
\text { excluded(rule }(1, \\
\text { borrowed_from }(x, y, \text { amount }) \\
\Rightarrow \text { owes }(x, y, \text { amount })))\end{array}$ \\
\hline \multirow[t]{2}{*}{19} & Arbiter & $\begin{array}{l}\text { valid(rule(2, loan_more-than- } \\
\text { thirty-years-old } \Rightarrow \\
\text { excluded(rule }(1, \\
\text { borrowed_from }(x, y, \text { amount }) \\
\Rightarrow \text { owes }(x, y, \text { amount })))\end{array}$ & & & \\
\hline & & $\begin{array}{l}\text { The arbiter decides } \\
\text { that the rule is } \\
\text { valid. }\end{array}$ & 20 & Claim & loan_more-than-thirty-years-old \\
\hline 21 & Accept & $\begin{array}{l}\text { loan_more-than-thirty-years- } \\
\text { old }\end{array}$ & 22 & Claim & $\begin{array}{l}\text { outweigh(Reasons_for, } \\
\text { Reasons_against, } \\
\text { excluded(rule( } 1, \\
\text { borrowed_from }(x, y, \text { amount }) \\
\Rightarrow \text { owes }(x, y, \text { amount }))\end{array}$ \\
\hline 23 & $\begin{array}{l}\text { With- } \\
\text { draw }\end{array}$ & owes $(\mathrm{B}, \mathrm{A}, \$ 10,000)$ & & & \\
\hline
\end{tabular}

In natural language, the dialogue in the table runs as follows:

A claims that B owes him ten thousand dollars. When B questions this, A adduces the fact that B borrowed the money from him as a reason (move 3). When B also questions this reason, A adduces the application of rule 1 to establish the reason (move 5). This application is also questioned by $\mathrm{B}$, and as a defence A retorts that this rule is applicable.

In move $8 \mathrm{~B}$ posits that the application of rule 1 is excluded. After questioning by $\mathrm{A}, \mathrm{B}$ adduces that fact that the loan was more than thirty years old as a reason for the exclusion.

A questions whether this is a valid reason. To back up his claim about the exclusion, B adduces the application of a rule. When A questions this application, B claims that the rule is applicable. When the applicability of the rule is also questioned too, B first claims that the rule is valid, and when this is questioned too, he invokes the arbiter (move 18). (B was in no position to argue for the rule, since A was not committed to this rule, nor to a rule on the basis of which could be argued for the rule.) A does not protest against this invocation, and the arbiter decides that the rule adduced by $\mathrm{B}$ is a valid one.

B continues to claim that the condition of the rule is fulfilled. A accepts this claim and B makes his final move: he claims that the reasons for exclusion of A's rule outweigh the reasons against exclusion. A gives up: he must accept the exclusion-claim of $\mathrm{B}$, and looses his only reason for his original claim. Therefore he immediately withdraws this claim. With this withdrawal, the dialogue ends.

Because in the course of this dialogue the arbiter made a decision, the case of this dialogue turned out to be a hard one. If $\mathrm{B}$ had not invoked the arbiter, but had withdrawn his claim that rule 2 is a 
valid one, the case might not have become hard. Probably B would have had to withdraw his exclusion-claim too, and then he would have had to accept the application of rule 1 . This results in the acceptance of a reason for the original claim of $\mathrm{A}$, and - in the absence of reasons against this claim - in the acceptance of A's original claim. In this hypothetical course of the dialogue, the arbiter does not play a role, and the case does not become hard.

\subsection{A short evaluation of Dialogical Reason Based Logic}

In section 3. we drew up a list of the demands on legal knowledge systems, that stem from the procedural approach to legal reasoning. Does DRBL live up to these demands?

In accordance with the first demand, DRBL does not model a logical relationship, but a procedure. DRBL by itself does not indicate which conclusions are derivable from which premises. Instead it provides a setting for dialogue moves, and it indicates the consequences of these moves. It does not generate the moves itself, but it expects input form 'outside' (c.f. demand four). Depending on this input, mutually incompatible dialogues can be generated.

Since DRBL has a top down approach to arguments, the 'premises' of the argument are introduced in the course of the argument. This reflects the second demand.

The dialogue rules in DRBL are just part of the total set of rules. In principle, all rules, including the dialogue rules, can be questioned, so the third demand is also met.

It appears that DRBL satisfies all four demands on a legal knowledge system, that we made in section 3. from a procedural perspective on legal arguments.

\section{THE VALIDITY OF OUR DEFINITION OF HARD CASES}

A case is hard if an a-rational decision making procedure is involved in determining its outcome. In terms of DRBL, this is translated into an invocation of the arbiter. It should be noted, however, that the specification which is made possible by the framework of DRBL, is only the formal counterpart of a general definition of hard cases. The arbiter in DRBL is an artificial technique used to represent the cutting of knot which is not performed by one of the parties involved in the dialogue. In the following sections we want to discuss whether this technique provides us with a suitable means to identify hard cases.

\subsection{The call to the arbiter}

To evaluate our formal definition of hard cases, we must pay some more attention to the call to the arbiter. There are two aspects of the call to the arbiter that are essential for our definition of hard cases. The first aspect concerns the lack of a rational solution to the case, operationalised as the demand that there is no winning strategy available. The second aspect concerns the fact that a dialogue party must actually invoke the arbiter. It is not sufficient that there is no rational solution; it is also essential that the parties in the dialogue do not solve the resulting problem themselves.

The rationale behind the rule that the arbiter can only be invoked if the case has no rational solution has already been discussed in section 5.8. The demand that the parties actually invoke the arbiter expresses the procedural character of our approach. The absence of a rational solution, however this may be defined, is a theoretical characteristic of a case that needs not be recognised by the parties in a legal dispute. If both parties agree to a particular solution for the case or an issue that arises in connection with the case, the case is not hard. Our example at the beginning of 
this article illustrates this possibility. A less gifted lawyer does not find the right reasons against the seemingly obvious solution, and the case, which might have been made a hard one, is solved as a clear one.

\subsection{Sentences at the disposal of the dialogue partners}

There is an obvious objection against the claim that a case is only hard, if the parties recognise the absence of a rational solution by means of a call to the arbiter. If, for instance, the dialogue parties prevent a threatening deadlock by agreeing on some obviously invalid rule, this does not show that the case was not hard.

An example may illustrate the point. Suppose that the outcome of a dialogue hinges on the question whether the refusal of one party to help the other party after a minor car accident amounts to a tort. Let us assume that an issue like this has never been decided before, and that there are no other obvious reasons to accept either answer to the question. Are the dialogue parties in a case like this capable to pass the issue whether there is a tort, by mutual agreement that the behaviour was tortuous? (That the tortfeasor would agree becomes more plausible if we assume that he defends himself by denying the causal connection between the tort and the damage.)

It seems that the dialogue parties, if they are the plaintiff and the defendant, are not free to decide whether the behaviour was tortuous or not. At least in Dutch law, this issue would be considered to be a legal one, and consequently not the subject of decision making by the parties in a law suit. The sentence that particular behaviour is tortuous is, to put a name on it, not at the disposal of the parties.

In Dutch law, issues of fact in civil procedures are at the disposal of the parties in a suit. Legal issues are not at their disposal, nor are the facts in a criminal procedure. Does this mean that the dialogical approach only works for a rather limited number of sentences? If so, this would amount to a refutation of the thesis that law is the outcome of a rhetorical procedure.

However, legal procedures need not always be dialogues between the parties in a law suit. We have already mentioned the possibility of so-called interior dialogues, in which a person conducts a dialogue with himself. Another possibility is that a dialogue is conducted between a trial party and the judge(s) of the case. Legal issues are not at the disposal of the parties in a trial, but they are at the disposal of the dialogue parties if one of the parties is a legal official.

Apparently it makes sense to distinguish between the status of the dialogue parties in determining whether a case is hard or not. If there is no rational solution for a case, the case is nevertheless clear if the issue of the case is at the disposal of the dialogue parties and the parties solve the issue without a call to the arbiter. If the parties 'solve' an issue that is not at their disposal, the case can still become hard if there is no rational solution for it.

The distinction between sentences which are, and sentences which are not at the disposal of particular dialogue parties provides us with a reason to treat certain legal procedures as debates between three parties.

\subsection{The absence of a rational solution}

If a case has a rational solution, a dialogue party should not be capable to transform the case into a hard one by invoking the arbiter. This does not mean that in reality parties may only invoke a judge if their case has no rational solution; it only means that such an invocation by itself does not 
turn a clear case into a hard one. The prohibition to call upon the arbiter in rationally solvable cases is only a device in a computational procedure to identify hard cases.

The role of this prohibition in a computational procedure also explains the operationalisation of the concept of a rational solution as the availability of a winning strategy. Somehow the informal notion of the availability of a rational solution was to be translated into the terminology of DRBL. Now the time has come to question this operationalisation. Does a winning strategy for a sentence in DRBL really correspond to a rational solution for a case in real life? To answer this question, we will first discuss the notion of a rational solution of a case.

The notion of rationality is rather tricky, and we will not try to provide a general theory of rationality here ${ }^{27}$. In connection with the solution of a legal case, we can distinguish two elements of a rational solution. A rational solution is based on generally accepted knowledge, and it should follow 'logically' from that knowledge.

With regard to this latter demand we must distinguish between rational solutions in the sense of solutions that are not irrational, and solutions that are dictated by reason. A solution that is not irrational is a solution that is compatible with the demands of reason. For our discussion of hard cases we are interested in the other sense of a rational solution, the solution that is dictated by reason. This is a solution for a case that 'logically' follows from the facts of the case and generally accepted knowledge.

We place the word 'logically' between parentheses, because we do not want to identify the notion of a logical consequence with a particular system of logic. Rather we think that a solution logically follows from a particular amount of information (data and knowledge) if this solution can be derived from the information by means of a generally accepted procedure. This procedure may in particular contexts (e.g. mathematics) be the one prescribed by a system of formal logic, but it may also consist of a number of (sometimes implicit) procedural rules, as it is the case in the law.

It turns out that both elements in our theory of rationality contain the notion of general acceptance. A rational solution is based on generally accepted data and knowledge, and it is derived from that information by means of a generally accepted procedure. This circumscription of rationality makes rationality into a social phenomenon, and that is exactly what we think it is ${ }^{28}$. This circumscription makes it, however, also clear why it is so hard to determine in a computational manner whether a case is a hard one. General acceptance is a dispositional notion defined over groups of people. A rule, for instance, is generally accepted within a group, if most members of the group would accept it at most occasions. This test for general acceptance is not something which can at present be implemented in a computing system.

The alternative is to make a list of generally accepted facts, knowledge, and procedural rules. Such a list will, however, always run the risk of being incomplete, wrong, or deficient in some other way. If we have a good computer implementation of what is generally accepted, the outcome of a computer model will provide a good indication of whether a case is hard or not. If

27 The reader who is interested in such a theory is referred to Brown 1988 and the literature mentioned there.

28 This does not mean that we think that 'the majority is always right'. A social theory of rationality is compatible with the view that the majority is irrational in a particular case, although it is not compatible with the view that the majority of recognised experts is always irrational. Cf. Kuhn 1970, p. 237/8. 
the computer implementation is not so good, however, the outcome is not very interesting (except for the knowledge engineer who must improve the system).

The possibility that the represented information is inadequate does not seem to create a very serious objection against representing what is generally accepted. Yet, the matter is not as simple as it may seem. In real life there is also an unavoidable uncertainty about what is generally accepted. The only data on which one can go, concern acceptance by individuals on particular occasions. Even if, for instance, a particular rule is generally accepted, it may be arguable that it nevertheless should not be accepted. If such an argument succeeds (on the basis of other rules that are generally accepted), the rule may nevertheless still be considered unacceptable, and will not be used.

Phenomena like this one are the reason that actual procedures do not rely on fixed premises, but rather work toward actual agreement on the basis of procedural rules. In a legal trial, everything may be the topic of a discussion, although not every position has a real chance of being accepted. For instance, an argument that starts from the presumption that the Constitution is legally completely irrelevant, does not make much chance to succeed. On the other hand, even such an argument, if very good reasons are produced for neglecting the Constitution, might at least in theory be successful and lead to valid legal conclusions.

The fundamental open nature of legal arguments is just the other side of the medal, the one side of which is the purely procedural nature of the law. A computational system that takes any set of facts or rules (material or procedural) as an unalterable given, deviates by that very fact in a fundamental sense from legal reality.

The two factors that are relevant to determine whether a case has a rational solution, viz. commonly accepted information and commonly accepted procedures, have in DRBL their counterparts in the commitment stores and the procedural rules of DRBL contained in them. Whether there is a winning strategy available for a sentence depends on the sentences to which the dialogue parties are committed.

There is a close parallel between the notions of a rational solution in legal practice and of a winning strategy in DRBL. This means that the framework of DRBL is a suitable one for the detection of hard cases, at least if our views of hard cases and of rational solutions are correct. This does not mean that every version of DRBL is equally suitable to deal with hard cases.

Different versions of DRBL are characterised by different sets of dialogue rules. We have seen that procedural rules are not something that is given independent of the group whose reasoning is concerned. The social nature of rationality reflects itself in the relativity of procedural rules. To deal adequately with hard cases in a particular reasoning practice, the dialogue rules of DRBL should reflect the actually accepted procedural rules.

In a similar fashion the generally accepted information of a legal reasoning community should be reflected in the commitment stores of the reasoning parties. If a party is committed to a sentence, this sentence can be 'used against him'. However, the commitments of the parties are not something that is unalterable. In principle it is possible to remove any sentence from one's commitment store by producing the right arguments against it. This reflects the rhetorical nature 
of the law: nothing is fixed. Everything can be brought up for discussion, even though not every position can be argued successfully ${ }^{29}$.

Resuming the argument of the last two sections, we can conclude that, given our procedural account of hard cases and of the rational solution of a case, the computational approach to hard cases as proposed in section 5.9. appears to be a valid one. The notion of a winning strategy, based upon particular commitments and dialogue rules, accurately reflects our definition of a rational solution of a case. The demand that the arbiter is actually called upon to decide a particular sentence reflects the phenomenon that a case is only hard if it is recognised as such by the parties involved in a legal procedure.

Apparent objections to the effect that parties may overlook difficulties which every reasonable person would see are remedied by the recognition that the parties in a dialogue are not capable to dispose over every sentence. For some sentences, the parties need not convince each other, but they need to convince the legal official. The dialogue then turns into a kind of three party-debate. The following extended discussion of an actual hard case from Dutch civil law illustrates this phenomenon.

\section{POST-TRAUMATIC NEUROSIS; AN ACTUAL HARD CASE}

In the following sections we analyse a case which turned out to be important in the development of the theory of causation in the Dutch civil law. At the time the case was presented at court it proved to be a hard one. In our analysis we discuss the arguments adduced in the case within the framework of DRBL.

One of our purposes with our analysis of the post-traumatic neurosis case is to illustrate the interwovenness (if not inclusion) of legal dialogue rules with (in) the rules of a legal system. We serve this purpose by pointing out actual argument steps and their (presupposed) rules that do not fit in the relatively simple set of rules presented above. However, we do not consider this as a demonstration of the failure of the set of rules, but rather as an illustration of the many forms in which dialogue rules can occur. Moreover, even the deviations from the dialogue rules we proposed do not preclude our analysis from illustrating the feasibility of our theory about hard cases. Indeed, our theory is based on the general framework of DRBL, and not on a particular instantiation of it in the form of concrete dialogue rules.

\subsection{The roles of the Courts}

The case passed the District Court (Rechtbank), the Court of Appeal (Hof) and the Netherlands Supreme Court (Hoge Raad) in this order. The first question we want to address, regards the role of the Court in proceedings as the present one. At first sight, it would seem that the Court is the arbiter in the dialogue between the two parties. However, this view would be too simple. The parties in a Dutch law suit are not free to employ their own rules of law. This means that if one party adduces a rule, and the other party accepts it, this does not guarantee that the rule will be applied in the verdict of the Court. Moreover, the very fact that the Court must give a verdict and react to the arguments of the parties, implies that somehow the Court is involved in the dialogue.

29 Remember that a party can withdraw a sentence S from his commitment store if he has committed the other party to the sentence that the reasons against $\mathrm{S}$ outweigh the reasons that plead for $\mathrm{S}$. One should realise in this connection, however, that not every sentence is at the disposal of every dialogue party. Two trial parties will not be able to change the rules of law simply by agreeing that there are convincing reasons against them. 
Maybe we should consider the possibility that the dialogue really is between the claimant and the Court. The claimant asks the Court to give a particular verdict and must therefore convince the Court that this verdict is the correct one. This view is hampered by the fact that the defending party also has an influence on the course of the dialogue. Indeed, in civil procedures, the claimant and the defendant together determine to a large degree the course of the procedure.

We must conclude that the model of two parties who have a dialogue before an arbiter is too simple to account for civil procedures in Dutch law. Actually we have a three party procedure, where one party - the Court - has a restricted role in the debate, and this party must play the arbiter too.

At the Court of Appeal, the parties of the discussion were appellant O., the District Court, and the Court of Appeal ${ }^{30}$. The latter also was the arbiter. At the Netherlands Supreme Court, the discussion was between the appellant in cassation W., the Court of Appeal, and the Netherlands Supreme Court, which was also the arbiter.

Of course in the second and the third instance there was no real discussion between the appellant and respectively the District Court and the Court of Appeal. The appellant questioned the decision and the argumentation presented by the Court at the previous instance. The Courts were not enabled to defend their opinions. Nevertheless, we hope our discussion shows that this deviation from the normal course of a dialogue does not prevent a dialogical analysis of the discussion from being fruitful.

\section{2. $\quad$ The case at the District Court}

The case was first brought to the District Court with a claim from W. to the defendant O. to pay a certain amount of money. To support this claim, W adduced (amongst others) the following facts: On May 31, 1961 the late husband of O. drove with a speed of a hundred kilometres an hour through the bend on the left side of the road (which is in the Netherlands the wrong side). There was a head-on collision with $\mathrm{W}$., who drove both literally and figuratively on the right side. As a result of this collision, the husband of O. died. As a further result, W. suffered from both physical and psychological injury. Moreover, W. became temporarily unable to work.

The facts adduced by $\mathrm{W}$. were not disputed by $\mathrm{O}$. and therefore both $\mathrm{W}$. and $\mathrm{O}$. are committed to them. From the perspective of DRBL this is an interesting phenomenon. Just by not disputing the facts adduced by W., the party $\mathrm{O}$. becomes committed to these facts. Explicit acceptance, as demanded by the rules that were previously presented, is not necessary in Dutch civil pleading. The question whether the facts are actually true does not arise, and the arbiter cannot influence whether these facts count in the discussion. Since both disputing parties are committed to them, the arbiter is committed too. In civil cases, the passive role of the courts regarding the facts is a principle of procedural law in the Netherlands, which can also be considered to be a rule governing legal dialogues. In terms of DRBL, this would be a commitment rule that states that if one of the opponents claims some facts, which are not questioned or denied by the other opponent, both opponents and the third party are committed to these facts.

Although O. was committed to the facts as stated above, she disputed W.'s claim. To support her position, O. stated that only in September $1961 \mathrm{~W}$. developed a neurotic depression which

30 It is worthwhile to consider the introduction of a fourth party, namely the defendant W. This party does, however, not occur in the law report on this case. 
resulted in his being unable to work until April 21st, 1962. Such a neurotic depression is, O. argued, not a consequence of a collision which can reasonably be expected according to rules of experience.

To understand this defence, one should know that during a long period before the case in question, the Dutch Supreme Court held that the damages to be recovered for torts were confined to those which could, according to rules of experience, reasonably be expected as a consequence of the injury. In terms of DRBL, this means that this rule was in the commitment stores of all three parties. If the defence of $\mathrm{O}$. is accepted, this would normally imply that $\mathrm{O}$. wins. The case would then be a clear one.

The Dutch Law Report (Nederlandse Jurisprudentie) does not state whether this defence was disputed by W. However, it does state that it was not accepted by the District Court. The Court held that the foreseeability of a post-traumatic neurosis like the one in question is not excluded by the fact that it would not have occurred to a person with a different personality structure than W.'s. According to the Court, all characteristics of W. and his personality should be taken into account in assessing the causal relationship between the tort and the damages.

This position of the Court can mean either one of two things. The first possibility is that W. disputed the support O. provided for her position. The second possibility is that the Court considered the question about the foreseeability of the damages a legal one.

If the first possibility was the case, there was a disagreement between $\mathrm{W}$. and O. about the facts of the case, especially about the causal relationship between the tort and the damages. This disagreement concerned the question whether the damages were according to rules of experience reasonably to be expected. Given the arguments provided by the Court, the discussion about this fact must have been focused on the question whether exceptional personal traits of a victim should be taken into account in assessing the reasonable foreseeability of the damages. This question is one about a rule of inference in factual matters. W. and O. disagree about its acceptability and therefore the Court must decide.

According to this analysis, the case turns out to have been a hard one. The disagreement between the parties was based on a disagreement about a rule of inference which was not in any commitment store. Neither party produced sufficient reasons for either accepting or rejecting this rule, and therefore the Court had to take a decision which was, at least from the legal perspective, an a-rational one. Given this a-rational decision, the outcome of the legal case can for the remaining part be determined rationally. Since, according to this analysis, the rational outcome presupposed an a-rational decision, the case was a hard one.

\begin{tabular}{|l|l|l|l|}
\hline & \multicolumn{1}{|c|}{ Party O. } & & \multicolumn{1}{c|}{ Party W. } \\
\hline Claim & $\begin{array}{l}\text { The neurotic depression is not } \\
\text { caused by the collision. }\end{array}$ & Question & $\begin{array}{l}\text { The neurotic depression is not } \\
\text { caused by the collision. }\end{array}$ \\
\hline Claim & $\begin{array}{l}\text { reason(Such a neurotic } \\
\text { depression could not be } \\
\text { reasonably expected according to } \\
\text { rules of experience, The neurotic } \\
\text { depression is caused by the } \\
\text { collision, con) }\end{array}$ & Question & $\begin{array}{l}\text { reason(Such a neurotic } \\
\text { depression could not be } \\
\text { reasonably expected according } \\
\text { to rules of experience, The } \\
\text { neurotic depression is caused by } \\
\text { the collision, con) }\end{array}$ \\
\hline Claim & $\begin{array}{l}\text { Such a neurotic depression could } \\
\text { not be reasonably expected } \\
\text { according to rules of experience. }\end{array}$ & Claim & $\begin{array}{l}\text { Such a neurotic depression } \\
\text { could in fact be reasonably } \\
\text { expected according to rules of } \\
\text { experience. }\end{array}$ \\
\hline
\end{tabular}




\begin{tabular}{|c|c|c|c|}
\hline Question & $\begin{array}{l}\text { Such a neurotic depression could } \\
\text { in fact be reasonably expected } \\
\text { according to rules of experience. }\end{array}$ & Claim & $\begin{array}{l}\text { reason(A person with a different } \\
\text { personality structure would not } \\
\text { have developed such a neurotic } \\
\text { depression, Such a neurotic } \\
\text { depression could in fact be } \\
\text { reasonably expected according } \\
\text { to rules of experience, pro) }\end{array}$ \\
\hline \multirow[t]{2}{*}{ Question } & $\begin{array}{l}\text { reason(A person with a different } \\
\text { personality structure would not } \\
\text { have developed such a neurotic } \\
\text { depression, Such a neurotic } \\
\text { depression could in fact be } \\
\text { reasonably expected according to } \\
\text { rules of experience, pro) }\end{array}$ & Arbiter & $\begin{array}{l}\text { reason(A person with a different } \\
\text { personality structure would not } \\
\text { have developed such a neurotic } \\
\text { depression, Such a neurotic } \\
\text { depression could in fact be } \\
\text { reasonably expected according } \\
\text { to rules of experience, pro) }\end{array}$ \\
\hline & $\begin{array}{l}\text { Arbiter: } \text { (reason (A } \\
\text { person with a } \\
\text { different personality } \\
\text { structure would not } \\
\text { have developed such a } \\
\text { neurotic depression, } \\
\text { Such a neurotic } \\
\text { depression could in } \\
\text { fact be reasonably } \\
\text { expected according to } \\
\text { rules of experience, } \\
\text { pro)) }\end{array}$ & & \\
\hline
\end{tabular}

If the second possibility was realised, there was a legal dispute about whether personality traits of a victim should be taken into account in assessing the causal relation between tort and damages. Essentially, the question is the same as in the first possibility, but with the important difference that it is now considered to be a legal one, that deals with the issue what counts as causation ${ }^{31}$. Again the case turns out to be a hard one, since the commitment stores of the parties do not yet contain a rule about the relation between personal traits of the victim and the reasonable foreseeability of damages. The Court is therefore not committed to any decision about the causal relation and must decide a-rationally.

In both possible interpretations of the course of affairs, the defence of $O$. caused the case to be a hard one. In the first interpretation the Court had to take a decision about the facts, since the parties were not committed to a single version of them. In the second interpretation, the Court had to decide a legal issue, which could have been avoided if neither party had raised it. In itself (whatever that may be), the case was neither hard nor clear.

\subsection{The case at the Court of Appeal}

O. took the case to the Court of Appeal and presented the following arguments for not being liable for the damages resulting from W.'s neurotic depression:

31 Notice that the interpretation of the concept of a cause is case-related in the sense that the criterion for the use of that concept is directly related to the case at hand. The question is neither what counts as a cause in general; nor is it whether there was in this specific case a causal link between tort and damages. The question is in between; it asks for a criterion (abstract) which provides a direct answer for this particular case (concrete). Cf. section 1 . 
1. the District Court should not have assumed on the ground of its own knowledge that the neurotic depression was a consequence of the tort which was reasonably to be expected on the basis of rules of experience;

2. in determining the causal relation between the tort and the damages, the District Court should have left out of consideration all those personal traits of W. which were not to be expected on the basis of rules of experience.

The first argument challenges the factual conclusion of the District Court about the causal connection between the collision and the damages. This conclusion was evidently considered to be a factual one, since the reasons suggest that an expert should have been consulted. If the conclusion were considered legal, the Court itself would have been the expert.

The question which is raised by this first argument is whether the Court has the power to decide on a specific factual question if the parties of the dispute cannot reach a common commitment. This is a question about the rules of the dialogue. The role of the arbiter in a dispute normally implies the power to decide on remaining factual questions. But the first argument adduced in appeal by O. contests this power, probably because the topic of the question asks for psychological expertise.

Notice that this discussion is not primarily about the facts of the case, but about the rules of the dialogue. In the terminology of DRBL, the first argument against the decision of the District Court is to be interpreted as a refusal to accept the claim of the Court that the neurotic depression was a consequence of the tort which was reasonably to be expected on the basis of rules of experience. It is not the truth of this claim that is contested, but the fact that this claim was made by the Court without first obtaining psychological expertise. 
We can put this argument in a table as follows (remember that a refusal is a claim that another claim is impossible):

\begin{tabular}{|c|c|c|c|}
\hline & Court & & O. \\
\hline Claim & $\begin{array}{l}\text { The foreseeability of a post- } \\
\text { traumatic neurosis like the } \\
\text { one in question is not } \\
\text { excluded by the fact that it } \\
\text { would not have occurred to a } \\
\text { person with a different } \\
\text { personality structure than W. } \\
\text { has. }\end{array}$ & Claim & $\begin{array}{l}\text { P( Claim (the foreseeability of } \\
\text { a post-traumatic neurosis like } \\
\text { the one in question is not } \\
\text { excluded by the fact that it } \\
\text { would not have occurred to a } \\
\text { person with a different } \\
\text { personality structure than W. } \\
\text { has.) }\end{array}$ \\
\hline Question & $\begin{array}{l}\sim \mathrm{P}(\text { Claim (the foreseeability } \\
\text { of a post-traumatic neurosis } \\
\text { like the one in question is not } \\
\text { excluded by the fact that it } \\
\text { would not have occurred to a } \\
\text { person with a different } \\
\text { personality structure than W. } \\
\text { has.) }\end{array}$ & Claim & $\begin{array}{l}\text { reason(Claims about the } \\
\text { foreseeability of a post-traumatic } \\
\text { neurosis like the one in question } \\
\text { demand for psychological } \\
\text { expertise, } \sim \mathrm{P} \text { (Claim (the } \\
\text { foreseeability of a post-traumatic } \\
\text { neurosis like the one in question } \\
\text { is not excluded by the fact that it } \\
\text { would not have occurred to a } \\
\text { person with a different } \\
\text { personality structure than } \mathrm{W} \text {. } \\
\text { has.), pro) }\end{array}$ \\
\hline
\end{tabular}

The second argument contests the interpretation of a rule adopted by the District Court in order to determine whether the damages of $\mathrm{W}$. were to be reasonably expected on the basis of rules of experience. In particular this argument proposes an alternative interpretation, according to which not all personality traits of the victim are to be taken into account, but only those which were to be expected on the basis of rules of experience.

In its reaction to these arguments the Court of Appeal starts with affirming the general rule about causation, which, the Court says, is adopted by both parties to the dispute and by the District Court. This rule, which can be considered present in all three commitment stores, states that only those damages can be considered as caused by the accident which were on the basis of rules of experience reasonably to be expected as a result from the accident. The disagreement is in the view of the Court of Appeal a disagreement about the proper interpretation of this rule.

The next step taken by the Court of Appeal is to determine the rationale behind the commonly accepted rule. In doing so, the Court relates the different possible interpretations of the rule to their consequences for the case at hand ${ }^{32}$. It strives for an interpretation according to which $\mathrm{O}$. would normally be liable if, although this may be unknown to the general public, the personality traits of W. occur more or less frequently. On the other hand, O. should not be liable if either the personality structure of $\mathrm{W}$. is so rare that it would not be reasonable to take it into account, or if a serious accident as the present one only very seldom leads to a neurotic depression like W.'s so that the traffic error of $\mathrm{O}$. cannot anymore be considered to be its cause.

32 Here we have an illustration of the phenomenon that a case related interpretation precedes an abstract one. The abstract interpretation is derived from the intended case related interpretation. 
In this connection, the Court of Appeal asked an expert whether a personality structure like W.'s is exceptional amongst drivers of a car. Presumably this can be considered as a partial acceptance of the first argument of the appellant. The Court of Appeal does not answer the question about the causal connection itself, but translates this question by means of its interpretation of the commonly accepted rule into a question about the frequency of W.'s personality structure. This last question is passed to an expert.

The answer of the expert was shaded. On the one hand, a personality structure which leads to a post-traumatic depression is not uncommon. On the other hand, such depressions seldom last more than four months. W.'s depression, however, lasted seven months, which is exceptionally long.

On basis of this answer the Court of Appeal drew the conclusion that $\mathrm{O}$. is liable for the damages as far as they were caused by the physical injury, and for the first four months of the neurotic depression. As a reason for this conclusion, the Court adduced that, although W.'s depression originated from the accident, its continuation must have resulted from other causes. In this way, the Court of Appeal distinguished the causal relation between tort and the existence of damage on the one hand, from the causal relation between the tort and the extent of the damage on the other hand.

In drawing this conclusion for the reasons it adduced, the Court of Appeal accepted an interpretation of the rule about causation which was not in the commitment store of any one of the parties. This does not mean that the Court of Appeal had no reasons for accepting that interpretation. In fact it explicitly mentioned reasons: Neither should one be liable for reasonably unforeseeable damages, nor should one be exempted from liability as a consequence of ignorance, however widespread that ignorance may be. The rule about causation adopted by the Court of Appeal, namely that one is liable for damages as far as they are reasonably foreseeable on the basis of not infrequent circumstances, is in accordance with these constraints. But the rule does not follow from the constraints, nor do the constraints follow from the rules of law in the common set. This means that the decision of the Court of Appeal was a-rational and that the case which the Court had to solve was a hard one.

\subsection{The case at the Netherlands Supreme Court}

W. took the case to the Netherlands Supreme Court. He argued that the decision of the Court of Appeal should be rejected. In this connection he essentially adduced that the Court of Appeal should not have attributed the continuation of the depression to other causes than the accident, without specifying these other causes or giving reasons for their existence.

The Netherlands Supreme Court now faced a hard question too. It had to decide about a rule proposed by the Court of Appeal, which has no rational foundation. There were hardly any reasons adduced against this rule. The appellant in cassation does not state more than that the arational decision of the Court of Appeal is incorrect. The Court of Appeal and the appellant proposed different interpretations of the law and the appellant did not even provide reasons for its interpretation.

Nevertheless the appellant won. The Netherlands Supreme Court decided that if somebody by means of a collision causes harm to somebody else, that first person is liable for the damages, even if the healing process takes longer than could normally be expected. To this general rule, which disposes of the distinction between the establishment and the extent of the damages, an 
exception can be made, if the tortfeasor proves that the unexpected extent of the damages is to be attributed to some other cause.

By this decision, for which the Netherlands Supreme Court did not give any reasons, the Court created a situation where law and procedure are intertwined. To evade liability, a tortfeasor has to take specific steps in a dialogue and must succeed in these steps. Again we have a situation in which substantive rules of law and rules of legal procedure cannot be separated.

\subsection{Conclusion}

This analysis of the case about post-traumatic neurosis illustrates some aspects of legal reasoning which fit well within a procedural framework. Three aspects are especially important. First there is the phenomenon of continuous interplay between substantive rules of law on the one hand and rules of procedure on the other hand. This interplay, which is amongst others illustrated by the division of the burden of proof and the role of experts in deciding technical factual questions, can only with difficulty be accounted for in a deductive framework.

Second it is the possible to include the rules of dialogue in the dispute. In a deductive framework, the only discussion which is possible is about the premises. The rules of inference are provided together with the system of logic. Of course, there are different systems which one can adopt, but none of these systems allows a discussion about the system itself.

Finally the case illustrates the complexity of the procedural rules that must cope with the roles of three parties involved in a debate.

\section{ALTERNATIVE APPROACHES}

Our analysis of hard cases has as its main tenet that a proper treatment of legal arguments deals with them as procedures, the outcomes of which determine the law. A case is hard, if in the course of such a procedure, an a-rational decision procedure is correctly employed. In the following sections, we will compare our theory about hard cases with some other views from the literature about legal theory and law and artificial intelligence.

\subsection{Analyses from legal theory}

As far as we know, the terminological distinction between hard and clear cases stems from Hart (1967). At least, the expression 'easy case' is introduced in that paper. Dworkin uses the expression 'hard cases' in Taking Rights Seriously (1978). But neither Hart nor Dworkin provides us with an analysis of what it means for a case to be hard (Hart 1961, 1967; Dworkin 1978, 1986; cf. also Gardner 1987, p. 191).

Hart and Dworkin offer us some analyses of how cases become hard ${ }^{33}$. Famous in this connection is the discussion by Hart (1958) of a concept's hard core of meaning and the penumbra of uncertainty. According to this discussion, the hardness of a case may stem from uncertainty about whether the case fulfils the conditions of a rule. Just as famous is Dworkin's analysis of the case Riggs v. Palmer, in which he argues that the application of a legal principle may prevent the application of a legal rule whose conditions are satisfied (Dworkin 1978, p. 23; 1986, p. 15 f.). But neither Hart nor Dworkin has even the intention to tell us what a hard case is. From their

33 Cf. section 1. about the difference between the nature and the causes of hard cases. 
theories, we can at most indirectly infer what the distinction between clear and hard cases amounts to.

\subsection{Berman and Hafner on indeterminacy}

Although the authors do not explicitly relate their theory about indeterminacy to the distinction between hard and clear cases, the description of indeterminacy which Berman and Hafner offer comes closer to a definition of a hard case than what most authors about hard cases present us. This description runs as follows:

By indeterminacy, legal scholars mean the ability to justify both sides of a legal question, using accepted legal principles to reach mutually inconsistent results. This is true even in cases where there is agreement on the facts and the applicable rules of law. Thus, the law as a decision-making system is "indeterminate" - in the majority of the cases, the decision could go either way.

In the context of their paper, which is about logic-based models of legal reasoning, we may assume that justification can be equated to logical deduction. The circumscription of indeterminacy then comes down to the ability to deduce inconsistent solutions for a case from accepted legal principles and (presumably) a description of the case.

Principles that are commonly accepted in the legal community are, in the terminology of DRBL, rules that are in the commitment store of the legal official. If the application of such principles, considered in themselves, leads to contradictory conclusions, there are valid reasons for incompatible solutions of a case. This is probably the situation meant by Berman and Hafner in their circumscription of indeterminacy.

Does the presence of reasons pointing in different directions necessarily mean that the law is indeterminate? No, since it may be the case that the relative weight of these reasons can be determined rationally. In that case, the reasons can rationally be weighed and the outcome determines the correct legal conclusion of the case. In the terminology of DRBL, one might say that a winning strategy exists, which makes use of information concerning the relative weight of reasons.

This situation illustrates the main tenet of Berman and Hafner's paper about indeterminacy. If the conflicting principles are treated as material implications in a system of deductive logic, the result would be an inconsistent set of premises. But the application of a legal rule or principle to a case should not be modelled as logical inference by means of modus ponens. Such logic-based models of legal reasoning are inadequate.

This situation also illustrates that the applicability of commonly accepted legal principles which point in different directions, does not necessarily lead to indeterminacy. Berman and Hafner correctly state that in the majority of cases the decision could go either way. The correctness of their position follows from the assumption that in the majority of cases there is no rational way to determine the relative weight of conflicting reasons. The framework of DRBL explains the phenomena adduced by Berman and Hafner to argue against logic-based models.

\subsection{Gardner's analysis of hard cases}

The distinction between hard and clear cases takes a central place in Gardner's work (Gardner 1987). Gardner offers an extensive discussion of the literature about this topic. However, she

neither defines hard nor clear cases, although she sometimes hints how they might be defined. For 
instance, she uses expressions like 'When the rules run out' (chapter 3), 'questions that could be seriously argued either way' (p. 16) and 'issues in which the human decision maker has some choice' (p. 190). These expressions, although not synonymous, might well be regarded as approximate definitions of hard cases. But, again, Gardner does not provide us with an explicit definition ${ }^{34}$.

Instead of a definition, Gardner offers heuristics to determine whether a case is hard. The first heuristic is that words in rules are used in their ordinary meaning (defined by a common sense rule), unless objections against using this ordinary meaning can be found. The second heuristic runs that 'if no answer about the satisfaction of a legal predicate can be derived using the CSK rules (common sense rules - the authors), then look for cases showing that the facts of the case at hand present an instance of one of the central kinds of situations that the predicate has been used to cover in the past'. And the third heuristic works the other way round: 'Whatever tentative answer has been derived, look for cases calling for the opposite answer' (p. 45 f.). If we take a closer look at these heuristics, we find that they indicate how to reason in cases which might be hard. They do not define hard or clear cases; nor do they indicate how hard cases are caused.

However, Gardner also presents an algorithm to recognise clear cases, which is closely related to these heuristics. It runs as follows: If the CSK rules do not even provide a tentative answer to the question of predicate satisfaction, one should try to match both positive and negative examples of the predicate against the case. If only positive or only negative matches exist, the case is considered clear; otherwise it is considered to be hard. If the CSK rules offer a tentative answer, this answer is assumed if neither positive nor negative examples match the case. The case is then considered clear. Otherwise the question whether the case is hard or clear is answered according to the first step of the algorithm (p. 54).

This algorithm gives us a way to recognise hard cases. It neither gives a definition, nor an explanation of why some cases are hard. It does however presuppose such an explanation. The algorithm assumes that the hardness of a case depends on whether it is easy to determine that the conditions of some rule are fulfilled. Moreover, it seems to assume that it is easy to determine whether the conditions of a rule are fulfilled if there are only reasons (cases) that plead for applicability, or only reasons (cases) that plead against it.

Whether the conditions of a rule are fulfilled is certainly an important factor in determining whether cases are hard or clear, but in our opinion it is not the only factor. A case may also be hard because the outcome of a clearly applicable rule is undesirable (Susskind 1987, p. 196/7), or because it is unclear whether a rule whose conditions clearly are not satisfied, must be applied analogously. Moreover, it may be easy to determine whether the conditions of a rule are fulfilled, even if there are both reasons for and against, if we have knowledge about the relative weight of these reasons.

Summarising, we conclude that Gardner does not offer a theory about the nature of hard and clear cases. But although Gardner does not offer an explicit theory, she describes a problematic situation which in our view comes close to the presence of a hard case. This is the situation 'When the rules run out'.

34 Possibly it was not the intention of Gardner's to give a definition of hard or of easy cases. Yet, it becomes difficult to judge the merits of a computational model of hard cases if it is not defined what the model is a model of. 
To appreciate this phrase as a description of what amounts to a hard case, we should consider what Gardner means by rules. It is, for instance, important that the rules Gardner has in mind need not be rules as formulated by the legislature. In her opinion, it is possible to represent a legal field which develops mainly through case law, by means of rules. If there need not be a close connection between the rules used for legal knowledge representation and rules used to create law, it is possible (although not necessarily adequate) to use rules for all knowledge which may be relevant for solving legal cases. If we adopt this policy, running out of rules comes down to running out of knowledge, which may in turn be interpreted as making a-rational decisions. If this view is the one Gardner holds, her theory about the nature of hard cases approaches ours. An important difference is that her view is based on a monological point of view, while ours is based on a dialogical point of view. Her monological approach makes it impossible for her to recognise that whether a case is hard or not depends on the behaviour of the parties involved in a legal dispute. Moreover, her approach does not recognise the importance of dialogue rules in legal procedures and consequently in determining the hardness of a case.

\subsection{Susskind's view of clear cases}

Susskind (1987) distinguishes between two senses in which a case can be clear. A case can be retrospectively clear, or it can be potentially clear. A case is retrospectively clear if the case is decided by a court and the court's findings confirm our own legal conclusions on some matter, and if the solution was in no way contentious. A case is potentially clear in the situation that if the case in question was brought to court, it would undoubtedly be decided in one particular way and thereby disposed of in a fashion with which none of us could reasonably quarrel.

According to Susskind, strictly speaking the only clear cases are the retrospectively clear ones. That is because all rules are open to implied exceptions, and the only reasoning agent who can authoritatively imply such an exception is a judge. The reason why a case can only be retrospectively clear, in our view, reflects the fact that whether a case is hard or clear depends on the reasons actually adduced in arguing that case. In this respect Susskind is correct.

In both definitions of clear cases, Susskind mentions both an element of expectation and an element of reason. The element of reason certainly is important in deciding whether a case is hard or clear. Expectation may, however, be quite unreasonable. If a case is decided according to the standards of reason, but against our unreasonable expectations, this does not mean that the case was, after all, not clear. It only means that our expectations were unreasonable. In DRBL this is taken into account by only allowing a party to invoke the arbiter if this party has no winning strategy available.

It appears that only the reason-elements should be maintained in Susskind's definitions of a clear case. But then the distinction between the two definitions collapses. The first definition becomes that a case is clear if the conclusion is in no way contentious. The second definition becomes that a case is clear if none of us can reasonably quarrel with its conclusion. In our view these definitions are approximately identical and both are imprecise versions of the definition provided by the theory of DRBL.

We find that the framework of DRBL provides us with means to assess Susskind's definitions of clear cases, to explain the attractive elements of these definitions and to justify our criticism to parts of them. 


\subsection{Case based reasoning and argument moves}

The research on legal case based reasoning has turned out to provide a starting point for dialogical (adversarial) analyses of legal reasoning. First the work of Ashley and Rissland on the HYPO project (Ashley and Rissland 1987; Ashley 1991) made clear the relation between cases and the roles they fulfil in adversarial legal reasoning. Building on this work, Skalak and Rissland pay explicit attention to the relation between cases and argument moves in the CABARET project (Rissland and Skalak 1991; Skalak and Rissland 1992).

In their paper 'Arguments and Cases: An Inevitable Intertwining' Skalak and Rissland (1992) give us an inventory of a number of recognised legal argument forms, and they illustrate how these argument forms can be used to reason with legal rules and cases.

We think that this type of research forms a very useful complement to analyses of legal reasoning as the one in the current paper. The framework of DRBL leaves the question open what are the precise dialogue rules for (parts of) the legal domain. The work on the CABARET project fills in part of the room left open by the framework of DRBL.

\section{GORDON'S THEORY ABOUT HARD CASES 35}

We devote some extra attention for the comparison between our dialogical approach to legal reasoning and the approach taken by Gordon. One reason is that it provides us with the possibility to illustrate how interpretation can be dealt with in the framework of DRBL. The other reason is that Gordon's approach is, as far as we know, the one which most resembles ours ${ }^{36}$.

\subsection{The abductive approach to legal arguments}

Essentially, Gordon's theory of hard cases comes down to the view that a case is hard if the available legal knowledge does not provide an answer to the main question of the case, or allows incompatible answers. The available legal knowledge is related to the course of a dialogue. To understand Gordon's views, it is necessary to know about his abductive approach to legal arguments. Basically this abductive approach comes down to the following. A legal argument consists of a number of premises and a conclusion $\phi$ that can be derived from these premises. The premises are in turn divided into three parts. First, there are facts and rules that are above dispute. Together they form the context $\Theta$ of the argument. Second, there are the facts of the case. Since these facts can be disputed, there can be different versions of them. The set $\Phi$ contains all interpretations of the facts of the case. Each particular legal argument contains a case description that is a member of $\Phi$. Finally there are the different interpretations of the law, that are evidently

35 In his (1991), Gordon presents a theory of easy cases (and consequently also of hard cases) that exhibits a number of similarities with our views. This theory of easy cases is embedded in a more general theory of legal issues which has been improved in Gordon's dissertation (Gordon 1993b). The dissertation does, however, not deal with hard and easy cases anymore. The following account of Gordon's views is based on the 1991-paper where his views on hard cases are concerned, while it is based on the dissertation where the topic of legal issues is concerned.

36 There are, of course, other dialogical approaches to (legal) arguments. Cf. MacKenzie 1979; Bench-Capon et al. 1991; Louie and Chen 1992; Vreeswijk 1992; Nitta et al. 1993. However, none of these exhibits a resemblance to our approach like Gordon's work does. 
mutually inconsistent. The set of all possible interpretations is called $\Sigma$. Particular (sets of) interpretations of the law, are abbreviated as $\Gamma$.

Most often, the facts of the case are considered to be above dispute, and then they are part of the context $\Theta$. In this case, a legal argument consists of a pair $(\Gamma, \phi)$, such that $\phi$ is derivable from the combination (set-theoretical union) of the context and the interpretation $\Gamma$ of the law.

$(\Theta \cup \Gamma \Rightarrow \phi)$

The abductive approach of legal arguments comes down to it that the essential step in such an argument is the adoption of a particular interpretation of the law, that leads to a specific conclusion for the case at hand. Depending on the chosen interpretation, the solution of the case may be different. Cf. figure 4 .

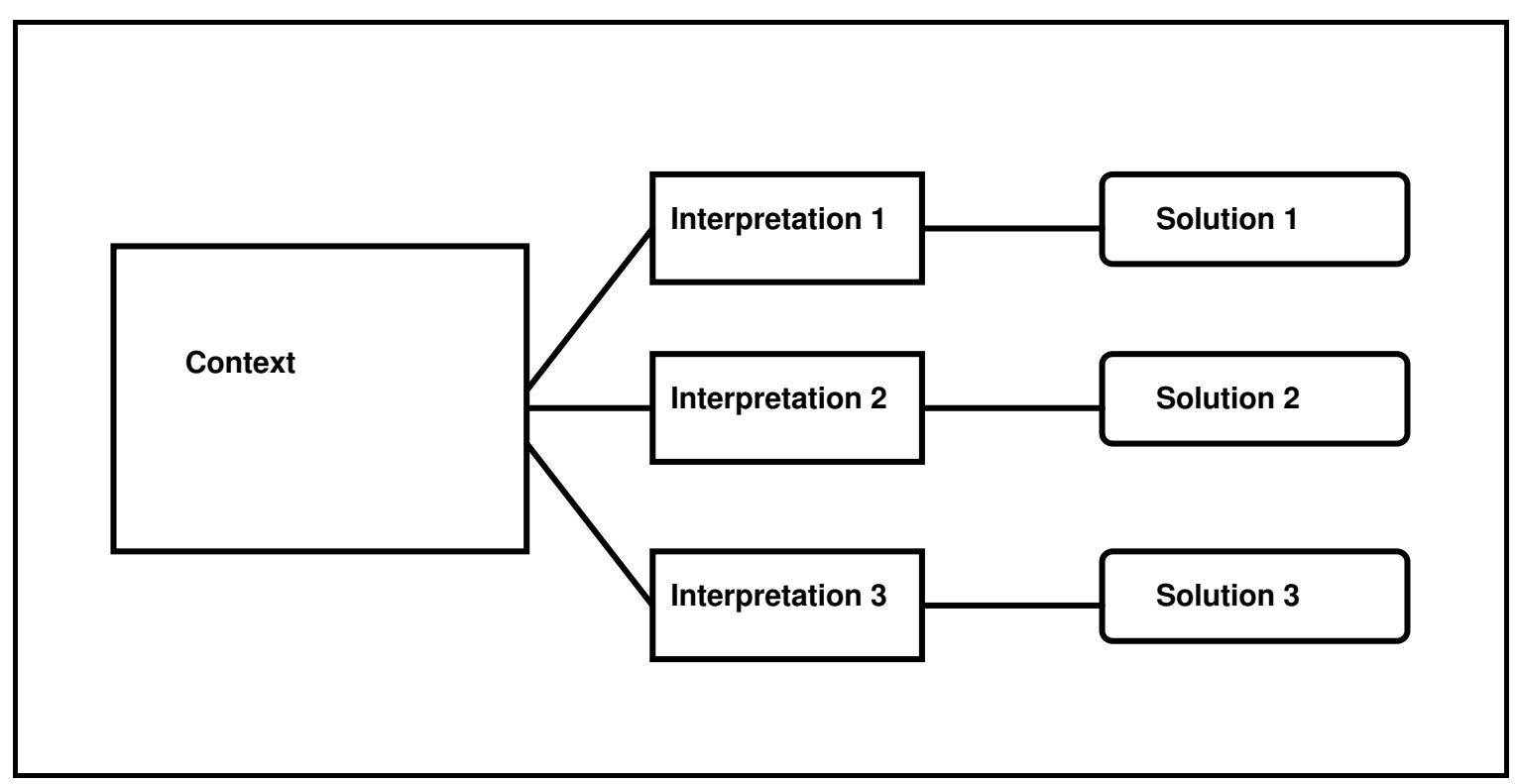

Figure 4: The abductive approach to legal arguments

\subsection{Clear cases and hard cases}

Starting from the abductive approach to legal arguments, Gordon defines clear cases as follows:

'A case is clear with respect to a goal $\phi$, given a set of interpretations of the law $\Gamma$, a set $\Phi$ of competing interpretations of the facts of the case, and a context $\Theta$ of uncontested facts, if and only if:

(1) The set $\Gamma \cup \Phi$ is neither overdetermined nor underdetermined with respect to $\phi$ in $\Theta$, or

(2) The set of potential issues is a subset of $\Phi^{\prime}$. (Gordon 1991, p. 109)

Informally, this definition of clear cases means that a case is clear if either the interpretations of the law and of the case allow of precisely one solution of the case, or, if they allow more than one solution, this is due to different interpretations of the facts of the case (and consequently not to different interpretations of the law).

If a case that is not clear is hard, hard cases are to be defined as follows: 
A case is hard with respect to a goal $\phi$, given a set of interpretations of the law $\Gamma$, a set $\Phi$ of competing interpretations of the facts of the case, and a context $\Theta$ of uncontested facts, if and only if:

(1) The set $\Gamma \cup \Phi$ is either overdetermined or underdetermined with respect to $\phi$ in $\Theta$, and

(2) The set of potential issues overlaps with $\Gamma$.

Gordon intends the set $\Gamma$ to be based on the law interpretations that are actually adduced by the parties in a legal dialogue. In this way he deals with the phenomenon that the set of relevant knowledge that is to be taken into account is not something given a priori, but is rather determined in the course of a legal procedure. In this respect his view is similar to ours. To see where his view differs from ours, we will discuss the notions of under- and overdetermination which are according to Gordon, relevant for the hard- or clearness of a case.

\subsection{Underdetermination}

Gordon defines underdetermination at first with respect to an interpretation of the law $\Gamma$, a context $\Theta$ and a specific legal question concerning that case $\phi$. $\Gamma$ is underdetermined with respect to $\phi$ if and only if $\Gamma \cup \Theta$ entails neither $\phi$ nor $\sim \phi$. This means that an interpretation of the law in combination with a description of the facts is underdetermined, if and only if it is not possible to derive an answer to a legal question from it.

This definition is later generalised to sets of interpretations in the following way:

A set of interpretations $\Gamma$ is underdetermined with respect to a goal $\phi$ in a context $\Theta$ if and only if for all consistent subsets $\Delta$ of $\Gamma$ :

1) $\operatorname{not}((\Delta \cup \Theta) \Rightarrow \phi)$, and

2) $\operatorname{not}((\Delta \cup \Theta) \Rightarrow \sim \phi)$.

Gordon mentions three possible causes of underdetermination. According to Gordon (1991, p. 107/8) underdetermination can result from:

a) open-textured or vague concepts;

b) the failure of the legislature to anticipate the particular case; or

c) the expression of the ratio decidendi of a precedent at too concrete a level of abstraction.

\subsection{Interpretation, open texture and vagueness}

The problems resulting from open texture or vagueness are in our view (as in Gordon's) clearly problems of interpretation. The question here is what the law is, or - more precisely - whether a specific part of the law is applicable to a particular case. If the law has been interpreted, the question whether the rule applies to the case has also been answered. There is no question of underdetermination.

Of course one may reply that underdetermination results if a sufficient interpretation is lacking. The vagueness or open texture of a legal concept or rule prevents interpretation of the law, and as a consequence it is impossible to decide whether the law is applicable to a specific case. In reaction to this reply we must distinguish between abstract and case related interpretation. An abstract interpretation of a concept or rule consists of a set of propositions which specify sufficient and/or necessary conditions for the applicability of the concept or rule. (For instance: Something is a vehicle, if and only if ...) A case related interpretation of a concept or rule 
consists of the decision whether the concept or rule is applicable to the case or not. (For instance: This is a vehicle in the sense of the prohibition of vehicles in the park ${ }^{37}$.)

Case related interpretation contains an element of classification. Classification of the case and interpretation of the rule go hand in hand to draw a conclusion about the applicability of the rule in this particular case. The process can artificially be divided in abstract interpretation on the one hand and classification of the case on the other hand. However, in making such a division, one easily neglects that the classification of the case depends on the abstract interpretation of the rule and the other way round. Classification and abstract interpretation are often the results of a process which primarily aims at a case related interpretation.

In the case of open textured concepts (and we believe that almost all concepts are open textured), it is not possible to give incorrigible abstract interpretations (Waismann 1949). Each abstract interpretation remains a hypothesis which can be challenged. This does, however not preclude us from devising abstract interpretations and solving cases by means of them. We should only keep in mind that since the abstract interpretations are not incorrigible, the solutions based on them are not incorrigible either. This is something different from underdetermination, however.

Moreover, as long as the open textured concept is not vague, open texture does not obstruct case related interpretation. Vagueness consists of problems with respect to case related interpretations. Vague concepts will always be open textured and consequently it will be difficult to provide them with lasting abstract interpretations. But in the case of vagueness, the lack of sufficient precise criteria of applicability manifests itself in interpretational difficulties for specific cases. In those cases there will be both reasons why the concept is applicable and reasons why the concept is not applicable (Dworkin 1986, p. 352). In opposition to open texturedness, vagueness itself is case related and is based on the availability of reasons that point in different directions.

\subsection{Reasons for interpretations}

The availability of more interpretations that lead to incompatible solutions for a case would, in the terminology of Gordon, not amount to underdetermination, but rather to overdetermination. If two of the possible solutions are incompatible, it will be possible to derive both $\phi$ and $\sim \phi$ from the set of interpretations and the background. This is precisely the case where different interpretations of the law lead to contradicting solutions for the case.

In our view the availability of more interpretations either indicates underdetermination (lack of knowledge), or has no implications for the hardness of the case at all. The reasons to choose for one of a number of competing law interpretations will also be reasons to choose against all of the competing interpretations. Each of the conflicting law interpretations will have zero or more reasons pleading for it, and zero or more reasons pleading against it. The choice between the possible interpretations depends on the reasons pleading for and against these interpretations. Either we have the knowledge which is necessary to decide rationally which interpretation is favoured by the available reasons, or we do not have this knowledge. In the first case, only one interpretation is rationally defensible and this interpretation should, if the dialogue parties are sufficiently clever, lead to the one correct solution of the case ${ }^{38}$. At least there will be a winning strategy for a solution based on this interpretation.

37 Cf. also the example in the post traumatic neurosis-case, in section 1.

38 We assume that the solution of the case solely depends on the choice of the 'correct' interpretation of the law. 
In the second case, there is no winning strategy for any solution available. In this sense the case can be said to be underdetermined. Whether it is also hard depends in our view on whether one of the parties invokes the arbiter. Hardness is not solely a logical property of a case, but also a matter of the actual course of a legal procedure.

\subsection{The ratio decidendi of a case and legislative gaps}

Formulation of the ratio decidendi of a case can be considered as a form of abstract interpretation of the case. If this leads to underdetermination, this is only the consequence of a specific way of interpreting the law, namely abstract instead of case related. The 'solution' to this problem is to reinterpret the older case, to determine what it means for the case at hand.

There may be conflicting interpretations of the case that are all defensible. In that case the situation is analogous to the situation where vagueness is responsible for several defensible interpretations of the law. The real problem is whether there is knowledge available to choose rationally between the reasons that plead for the different interpretations of the case.

Finally it is possible that the legislature has failed to anticipate to the particular case. Whether the legislator had some specific (type of) case in mind while drafting a statute is of importance for the case related interpretation of that statute. But given a specific interpretation, the conditions of a rule deriving from the statute are either fulfilled or not. There is no room for underdetermination here ${ }^{39}$.

If the legislator 'forgot' to make a statutory rule for some kind of case, there are again two possibilities. Either there exists applicable law in this kind of case, or not. (Not all legal rules need originate from statutes or from case law.) Which of these two is the case depends on the case related interpretation of the law. If there is applicable law, certain legal consequences will result. If there is no applicable law, no legal consequences will result. But again, in neither case there is room for underdetermination.

This does not mean that legislative gaps cannot lead to hard cases. It only means that the gaps do not lead to the specific form of hard cases which is called underdetermination. Gaps make it necessary to interpret the law ${ }^{40}$. It is possible that there are reasons for conflicting interpretations. Lack of knowledge about which interpretation should be preferred may, if an a-rational decision procedure is invoked, lead to a hard case. This cause of hard cases is, however, not unique for legal gaps, but is the classical problem of conflicting defensible law interpretations.

\subsection{Overdetermination}

According to Gordon the problem of overdetermination arises in case the law can be interpreted in different ways and the different interpretations lead to different outcomes of a specific case. Of course the different interpretations should all be defensible.

It will be clear that this situation is exactly the one we characterised as a case of underdetermination. The law does not give more than one answer to the case; the problem is that we do not (yet) know which answer is to be preferred. The 'correct' answer, if there is one, depends on the availability of a winning strategy, and this depends in turn on the reasons that plead for and against the different law interpretations and the knowledge that indicates which set

39 For the sake of argument we assume that rules are not applied analogously.

40 This is also necessary if there are no gaps, so this is not a sensational effect of gaps. 
of reasons outweighs the other sets. We find that overdetermination as a possible cause of hard cases comes down to underdetermination in our analysis.

\subsection{The difference between Gordon's views and ours}

Summarising, we can say that in Gordon's view a case is hard if the solution to that case is either over- or underdetermined on the basis of the law interpretations that are available (at a particular stage) in a legal dialogue. This view differs in four respects from ours.

The first respect has not yet been mentioned, because it is not very important for the central issue of this paper. Gordon (1993b) uses the theory of conditional entailment (Geffner and Pearl 1992) to determine whether a conclusion follows from a theory, while we employ a version of RBL. Conditional entailment does not allow the weighing of reasons, and can therefore not deal with a number of arguments that occur frequently in the law. This difference is important for the choice of a logic for legal knowledge systems, but not as far as the procedural nature of the law is concerned.

The second difference more or less follows from the first one. Because conditional entailment does not allow conflicting reasons, it must work with competing arguments for incompatible conclusions. This leads to an abductive approach where the conflicting reasons become inconsistent law interpretations. If these conflicting interpretations are taken together, the possibility of overdetermination arises.

In our view the different law interpretations are not considered as propositions in competing arguments. Instead we look at the reasons that plead for and against the several interpretations. If the knowledge that is needed to determine the relative weight of these reasons, is available, weighing reasons leads to the choice of one of the competing interpretations. If this knowledge is not available, this does not mean that the solution of the case is overdetermined, but rather that we do not have the knowledge to solve the case rationally. RBL makes overdetermination impossible; underdetermination is the only way to arrive at hard cases.

This brings us to the third, and one of the two most fundamental differences between our view and Gordon's. A case that is underdetermined (or overdetermined) because of a difference of opinion about the correct interpretation of the law is, in the view of Gordon, ipso facto a hard case. In our view, where underdetermination comes down to the absence of a winning strategy, this is only a logical condition. Next to the lack of a winning strategy it is in our view necessary that the case is in fact solved a-rationally. In terms of DRBL this means that the arbiter must have been invoked. The arbiter may only be invoked if there is no winning strategy, but even in the latter situation the parties in the debate can solve their problems themselves. If this happens, the case is not a hard one.

This third difference with the view of Gordon's may be a subtle one, but it is nevertheless essential. It is precisely the difference between an approach to legal reasoning that is fully procedural and an approach that is only partial procedural. Gordon employs dialogues to establish the set of propositions which determine whether a case is hard. However, the ultimate step is a logical one, as Gordon himself admits ${ }^{41}$. In our view the decisive step in making a hard case is procedural, namely the invocation of an a-rational decision making procedure.

41 Cf. Gordon 1991, p. 109, where it is stated that the definition of hard cases is an objective one. 
The fourth difference is that our approach makes it possible to discuss about the dialogue rules. This difference is in our view very important, because the dialogue rules are part of the domain knowledge. The open ended nature of legal arguments demands that all domain knowledge, including the dialogue rules can be drawn into discussion. If the dialogue rules are set apart, this comes down to an implicit claim that there exists an universal rationality, namely the rationality that is embodied in the fixed rules. We reject this claim, and the possibility to argue about the dialogue rules reflects this rejection.

\section{THE CAUSES OF HARD CASES}

The literature about legal knowledge based systems contains multiple listings of possible causes of hard cases. As was to be expected, the listings resemble each other very much. We mention three of these possible causes, namely the possibility that legal rules and principles conflict, the phenomenon that a piece of law allows of more than one interpretation, and the occurrence of 'hidden' or 'implied' exceptions to legal rules. We discuss the first and the last of these three and explain their effects in the framework of DRBL. In this way we hope to illustrate the fruitfulness of a procedural approach in making clear how the causes of hard cases actually make cases which lack a winning strategy.

As we have already noticed, the application of conflicting rules or principles to a case leads to incompatible conclusions (Berman and Hafner 1987; Susskind 1987; Gordon 1991). If the rules or principles are all valid, the case will often be a hard one. With the theory of DRBL it can easily be explained when and why this is the case. Conflicting rules underlie reasons which plead for and against the same conclusion. If there is no rational procedure to weigh these reasons, the case lacks a winning strategy.

In section 9.5. we have already discussed how the availability of more than one possible interpretation, that is the presence of reasons for conflicting interpretations, lead to underdetermination.

The problem of the hidden or implied exceptions arises in both of the two following situations. Either there is an exclusionary reason, or there is a (normal) reason against the rule's application. The presence of an exclusionary reason does not necessarily lead to a hard case. If, for instance, a more specific rule is applicable, it may be very clear that only the more specific rule is to be applied. If there are no conflicting reasons, the outcome of the more specific rule determines the solution of the case.

The case will only become hard if there are both reasons for and against the presence of an exclusionary reason. This is, for instance, the case if the more specific rule is older than the more general rule. Both the Lex Specialis rule and the Lex Posterior rule generate a reason; the one for application of the more specific rule, the other for application of the more recent rule. Only if there is no knowledge how to deal with this latter conflict, the case lacks a winning strategy. There is a reason against application of a rule if application would be against the rule's purpose. This reason will have to be weighed against the reason for application, namely that the rule is applicable. In the absence of the necessary weighing knowledge, the case may become hard. Concluding we can say that in all the three generally recognised causes of hard cases, we have the problem of conflicting reasons and the lack of decisive weighing knowledge. It turns out that whether a case is hard depends on the availability of the relevant legal knowledge and on the way in which the parties in a legal procedure deal with this lack of knowledge. 


\section{CONCLUSION AND FUTURE WORK}

We hope to have shown why it is important to take the procedural nature of law into account. The main reasons for doing so are that the law is open ended, that it is therefore not very useful to deal with legal reasoning as if it started from a fixed number of premises, and that legal dialogues (or more-party debates) provide us with a useful means to deal with this open ended nature. Moreover, the procedural approach to legal reason is in line with the view of the law as a rhetorical procedure.

The fruitfulness of the procedural approach was illustrated by means of an extended analysis of the phenomenon of hard cases. It turned out that a hard case has both a 'logical' and a procedural component. On the one hand, whether a case is hard or not depends on the actual behaviour of the parties involved in the debate. If they invoke an a-rational decision procedure, the case is hard; otherwise not. However, not every invocation of an a-rational procedure makes a case into a hard one. This is only the case if there was no rational procedure available that determines the outcome of the legal dialogue.

To take this latter demand into account, our formal counterpart of legal dialogues, the framework of DRBL, only allows a call to the arbiter if there is no winning strategy available. This framework is the basis of a formalised theory of legal dialogues. It is not such a theory itself, because the dialogue rules are (to a large extent) part of the domain that is to be modelled in the framework. This interwovenness of a domain and the dialogue rules for that domain are on the one hand the reason why DRBL only offers a framework for dialogical theories, and on the other hand why DRBL allows discussion about its own dialogue rules (via refusal).

Both the possibilities and the shortcomings of DRBL were made clear by an analysis of an actual Dutch hard case. One of the purposes of this analysis is to indicate direction for future research. Future work must certainly investigate the actual dialogue rules of particular legal (sub-)domains. The research of Skalak and Rissland (1992) provides an inspiring starting point for this.

Moreover, it is important to distinguish clearly between the rules that define the framework of DRBL, and which are - as far as DRBL is concerned, above discussion, and the rules that define particular domains and can be drawn into the discussion. It seems necessary to study a number of diverse domains to determine what is domain-dependent, and what is not.

Another direction of future work consists of the implementation of the DRBL-framework in an actual reasoning system. This work is already in progress. At the University of Limburg we are building a legal tutoring system that uses DRBL as a means to implement legal dialogues between a student and a computer (Hage et al. 1992; for a comparable approach cf. Ashley and Aleven 1993).

\section{ACKNOWLEDGEMENTS}

The authors wish to thank Tom Gordon, Anja Oskamp, Aernout Schmidt, Corina Roks, and the anonymous referees of Artificial Intelligence and Law for their suggestions for improvement. The work of the first author has partly been made possible by a grant of the Dutch Foundation for Knowledge Based Systems. 


\section{APPENDIX}

This appendix contains a semi-formal description of Dialogical Reason Based Logic. Because full formalisation is not necessary for the purpose of the present paper, we have chosen to use a mixture of natural and formal language as seemed suitable to improve readability.

The work on attractive sets of dialogue rules is still in progress. One disadvantage of the set proposed here is that a party can frustrate a winning strategy for a claim, by adducing a reason against this claim and engaging in a hopeless, yet endless defense of this counter-reason.

The text employs italics to denote variables. A vertical bar (I) between two words means that exactly one of the two words should be present. The ALTERNATIVE FONT is used to draw attention to expressions that are defined.

Although there are no principal reasons not to use first order predicate logic formulas for sentences in DRBL, we choose here for propositional logic for the ease of exposition. Moreover, we decided not to pay attention to the integration of e.g. propositional logic in DRBL.

\section{DEFINITIONS}

\section{Dialogue Games}

A DIALOGUE GAME consists of one or more dialogues. One of these dialogues is the MAIN DIALOGUE. The other dialogues are SUB-DIALOGUES of the main dialogue. A dialogue game begins when its main dialogue begins, and it ends when its main dialogue ends.

\section{Dialogue Parties}

In a dialogue game there are two PARTIES involved. The parties are each other's OPPONENTS.

\section{Commitment Stores}

Each party has a COMMITMENT STORE. A commitment store is the set of sentences to which a party is committed. The commitment store of a party $P$ is called CSP.

\section{Sentences}

A SENTENCE is a literal, or a conjunction of literals of propositional logic. (A literal is an elementary proposition, or its negation.)

A sentence is introduced in a dialogue by means of a claim. Therefore a sentence is sometimes referred to as the claim through which the sentence was introduced.

A sentence is said to be ESTABLISHED, if it occurs in the commitment stores of both parties. In an analogous way the word 'established' is also used for claims, rules, and reasons.

\section{Dialogue Moves}

A dialogue consists of a sequence of two or more DIALOGUE MOVES and zero or more ARBITER DECISIONS. A dialogue move is an illocutionary act applied to a sentence $S$. (Cf. Searle 1969 on illocutionary acts.)

$S$ is said to be the sentence of the dialogue move. The different illocutionary acts which can be performed by dialogue moves constitute the different types of dialogue moves. 


\section{Types of Dialogue Moves}

The dialogue moves are of the following basic types:

Claim: sentence,

Withdraw: sentence,

Accept: sentence,

Question: sentence,

Arbiter: sentence,

Pass. (Pass does not have a sentence.)

There are also derived move types:

Deny: sentence $=_{\text {def }}$ Claim: $\sim$ sentence. sentence is called the 'denied sentence'. (Double negations are dropped.)

Refuse: Claim: sentence $={ }_{\text {def }}$ Claim: $\sim P($ Claim: sentence $)$. Claim: sentence is called the 'refused claim'.

' $P$ ' should be read as 'possible'. The refusal of a claim comes down to the claim that the refused claim was impossible.

\section{Abbreviations}

A REASON-CLAIM for a sentence $S$ is the claim that some facts are together a reason for $S$. It is of the form reason(reason, $S$, pro).

A REASON-CLAIM against a sentence $S$ is the claim that some facts are together a reason against $S$. It is of the form reason(reason, $S$, con).

A VALIDITY-CLAIM is the claim that a particular rule is valid. It is of the form Claim: valid(rule(rule_id, rule_conditions $\Rightarrow$ rule_conclusion)), or valid(rule(rule_id)).

An APPLICABLE-CLAIM is the claim that a particular rule is applicable. It is of the form Claim: applicable(rule(rule_id,rule_conditions $\Rightarrow$ rule_conclusion)), or applicable(rule(rule_id)).

An APPLY-CLAIM is the claim that a particular rule applies. It is of the form Claim: apply(rule(rule_id,rule_conditions $\Rightarrow$ rule_conclusion)), or apply(rule(rule_id)).

An EXCLUDED-CLAIM is a claim that the application of a particular rule is excluded. It is of the form

Claim: excluded(rule(rule_id,rule_conditions $\Rightarrow$ rule_conclusion)), or excluded(rule(rule_id)).

An ABSTRACT WEIGHT-CLAIM is a claim that the reasons for a particular sentence $S$ outweigh the reasons against it, or the other way round. Abstract weight claims for or against $S$ have respectively the following forms:

Claim: outweigh(reasons_for, reasons_against, $S$ ),

Claim: outweigh(reasons_against, reasons_for, $S$ ).

An abstract weight-claim is said to be abstract, because it does not mention the reasons that plead for or against the sentence. The reasons are referred to by the expressions reasons_for and reasons_against, which respectively refer to the established reasons that plead for and against the thesis $S$.

A CONCRETE WEIGHT-CLAIM is a claim that a particular set of reasons outweighs another particular set of reasons with regard to a sentence $S$. It has one of the forms:

Claim: outweigh $\left(\left[R_{p 1} \ldots R_{p n}\right],\left[R_{c 1} \ldots R_{c n}\right], S\right)$, 
or

Claim: outweigh $\left(\left[R_{c l} \ldots R_{c n}\right],\left[R_{p 1} \ldots R_{p n}\right], S\right)$,

where $R_{p 1} \ldots R_{p n}$ are the reasons that plead for $S$, and $R_{c l} \ldots R_{c n}$ are the reasons that plead against $S$, A REFUSAL is a claim that says that another claim is not possible. It has the form

Claim: $\sim P($ Claim: sentence).

A STANDARD-CLAIM is a claim that is not one of the following: denial, validity-claim, applicableclaim, apply-claim, excluded-claim, abstract weight-claim, concrete weight-claim, or refusal.

An arbiter-call is an argument move of the form: Arbiter: sentence.

\section{Sub-dialogues}

If a claim is made in the course of dialogue $D$ and is not the claim of $\mathrm{D}$, the dialogue about this claim is said to be a sub-dialogue of $D$.

The sub-dialogue relation is transitive: If $D_{3}$ is a sub-dialogue of $D_{2}$, and $D_{2}$ is a sub-dialogue of $D_{1}$, then $D_{3}$ is a sub-dialogue of $D_{1}$.

\section{Open claims}

A claim is said to be open in a dialogue $D_{1}$, if both:

a. the dialogue $D_{2}$ about this claim has not ended yet; and

b. $D_{1}=D_{2}$ or $D_{2}$ is a sub-dialogue of $D_{1}$.

A claim $C$ is made directly within a dialogue $D$, if $C$ is the claim of some sub-dialogue of $D$, and there is no sub-dialogue $D^{\prime}$ of $D$ such that $C$ is made in a sub-dialogue of $D^{\prime}$.

\section{The Arbiter}

Next to the parties, there is an ARBITER. The arbiter does not make dialogue moves, but if he is called upon by means of an arbiter-call and this call is accepted, he is able to add sentences to, or remove sentences from the commitment stores of the parties.

Acceptance of a call to the arbiter for a sentence $S$ consists of another call to the arbiter for $S$.

\section{Winning strategy}

A party has a winning strategy for a sentence if there is a sequence of moves he can make such that this sequence forces his opponent to accept $\mathrm{S}$, however the opponent may defend himself.

\section{The Beginning of a Dialogue}

Each dialogue starts with a claim, and each claim starts a dialogue. The claimed sentence is called the thesis of the dialogue, and the dialogue is said to be about this claim, or about the sentence of the claim. The thesis of the main dialogue is called the main thesis of the dialogue game. The party who claimed the thesis of a dialogue is called the proponent of this dialogue; the other party is called the opponent of this dialogue.

\section{Commitment Stores}

At the beginning of a dialogue game, the commitment stores of both parties contain (at least) the following sentences:

$\operatorname{valid}(\operatorname{rule}(1,(S 1 \neq \varnothing) \&(S 2=\varnothing) \Rightarrow($ Sentence $)(\operatorname{outweigh}(S 1, S 2$, Sentence $)))$

$\operatorname{valid}(\operatorname{rule}(2, \operatorname{applicable}(\operatorname{rule}(R)) \Rightarrow \operatorname{apply}(\operatorname{rule}(R))))$ 
Moreover, these commitment stores also contain all of the dialogue rules in the form of DRBLformula's (sentences stating that these rules are valid ones).

\section{Termination rules}

rule 1 A dialogue about the sentence $S$ ends by the acceptance of $S$, by the withdrawal of $S$, or by an arbiter decision about $S$.

rule 2 If a dialogue ends, all of its sub-dialogues end.

\section{Commitment rules}

rule 3 Each party $P$ is committed to the sentences in $\mathrm{CS}_{\mathrm{P}}$.

rule 4 When a sentence $S$ is claimed by a party $P, S$ is added to $\mathrm{CS}_{\mathrm{P}}$, unless the claim is an abstract weight-claim.

rule 5 When a sentence $S$ is accepted by a party $P, S$ is added to $\mathrm{CS}_{\mathrm{P}}$.

rule 6 When a sentence $S$ is withdrawn by a party $P$, this sentence is removed from $\mathrm{CS}_{\mathrm{p}}$.

rule 7 If a dialogue $D$ ends because a sentence is accepted by party $P$, all open claims of $P$ in $D$ are removed from $\mathrm{CS}_{\mathrm{P}}$, and all open claims in $D$ of $D$ 's proponent are added to $\mathrm{CS}_{\mathrm{P}}$.

rule 8 If a dialogue $D$ ends because a sentence is withdrawn by party $P$, the sentences of all open claims of $P$ in $D$ are removed from $\mathrm{CS}_{\mathrm{P}}$, and the sentences of all open claims in $D$ of $D$ 's opponent are added to $\mathrm{CS}_{\mathrm{P}}$.

rule 9 If a dialogue $D$ ends because the sentence of this dialogue is decided by the arbiter, every open claim made in $D$ is removed from the commitment store of the party who made this claim.

\section{Dialogue rules}

rule 10 No dialogue move is possible, unless it is made possible by the following rules.

rule 11 A dialogue about sentence $S$ starts by claim: $S$. There is no other way to start a dialogue.

rule 12 A claim of the sentence $S$ can only be made by a party $P$ if $\sim S$ is not in $\mathrm{CS}_{\mathrm{P}}$, and $S$ is not in the commitment store of $P$ 's opponent.

rule 13 Both parties move in turn, unless it is indicated otherwise in one of the following rules.

rule 14 A procedure to establish a sentence starts with the claim of this sentence, and ends if the sentence has been established, or if the claim has been withdrawn.

rule 15 On every occasion when a party $P$ is not allowed to claim the sentence $S$ only because it is established that $\sim S, P$ can claim outweigh(reasons_for, reasons_against, $S$ ). If the dialogue about this abstract weight-claim has ended in its acceptance, $P$ must immediately withdraw $\sim S$ and claim $S$. If the dialogue about the abstract weight-claim has ended in a withdrawal of the weight-claim, $P$ has the choice from every move that was possible when he made the abstract weight-claim, with the exception of this weightclaim.

\section{Acceptance and withdrawal}

rule 16 The withdrawal of a sentence does not end ones turn.

rule 17 The proponent in an open dialogue about sentence $S$ can on any turn withdraw $S$.

rule 18 If a sentence $S$ is not the sentence of an open dialogue, a party can only retract $S$ if his opponent is not committed to $S$.

rule 19 A party $P$ can only accept a sentence $S$ if $S$ is not in $\mathrm{CS}_{\mathrm{P}}$. 
rule 20 A party $P$ can on any turn accept a sentence $S$, if $S$ is in the sentence of an open claim of $P$ 's opponent. Rule 17 is to be taken into account.

rule 21 The rules 17 and 19 are not superseded by the following rules.

\section{Immediate successors of claims}

rule 22 The immediate successor to a claim must be one of the following. If the claim is:

a. a standard claim of the sentence $S$ : question: $S$, claim: $\sim S$, or claim: $\sim P$ (claim: $S$ );

b. a denial of sentence $S$ : question: $\sim S$, reason(reason, $S$, pro).

c. a validity-claim of the rule R: question: $\operatorname{valid}(\operatorname{rule}(\mathrm{R}))$;

d. an apply-claim of the rule R: question: apply(rule(R));

e. an applicable-claim of the rule R: claim: applicable(rule $(\mathrm{R}))$, or claim: excluded(rule(R));

f. an abstract or concrete weight-claim for $S$ : questioning or denial of this weight-claim;

g. a call to the arbiter with regard to sentence $S$ : arbiter: $S$, or claim $\sim S$. The first reaction is only possible if the first mentioned claim to the arbiter was not already a successor to a claim to the arbiter;

h. the refusal of a claim of sentence $S$ : question: $\sim P($ claim: $S)$.

\section{The reasoning when a claim has been questioned}

rule 23 If a claim is questioned, the proponent of the claim must either defend the questioned sentence by means of reasons, or make a call to the arbiter with regard to this sentence if such a call is allowed.

rule 24 The proponent of a questioned sentence $S$ can at any moment in the dialogue about $S$, when it is his turn to move, make a call to the arbiter with regard to $S$, unless:

a. there is a winning strategy for $\mathrm{S}$ available; or

b. $S$ was an abstract weight-claim, an applicable-claim, or an apply-claim.

rule 25 After a call to the arbiter with regard to sentence $S$, the opponent of the calling party must either accept the call, or deny $S$. The latter possibility only exists if $S$ itself was not claimed as a denial, and if the denying party is not committed to $S$.

The party that answered to a call to the arbiter by a denial can at a later stage in the dialogue about $S$ accept the call to the arbiter for $S$, but only after the denial has been withdrawn.

After the arbiter has given a decision about $S$, it is the turn of the party who first called the arbiter.

If the arbiter has decided in favour of $S$, the party who is in turn can make every move that would have been allowed if $S$ would have been accepted, rather than questioned by his opponent.

If the arbiter has decided against $S$, the party who is in turn can make every move that would have been allowed if he would have withdrawn $S$ after the questioning of $S$ by his opponent.

rule 26 Unless indicated otherwise, the defence of a questioned sentence $S$ consists of four steps:

a. the establishment of one or more reasons for $S$;

b. the establishment of one or more reasons against $S$;

c. the establishment of one or more reasons for $S$;

d. the establishment of an abstract weight-claim for $S$. 
The steps b. and c. are facultative and can be repeated for an indefinite number of times, with the understanding that step c. can only occur if it has been preceded by step $b$.

The proponent who defends sentence $S$ indicates the end of phase a, or phase c. by making an abstract weight-claim for $S$. An abstract weight-claim for a sentence can only be made if at least one reason for this sentence has been established.

rule 27 If the proponent of a sentence makes an abstract weight-claim for the sentence $S$, the opponent can start the establishment of one or more reasons against $S$. This phase of the argument about $S$ ends by a pass of the opponent of $S$. After this pass, the proponent can either start the establishment of new reasons for $S$, or make an abstract weight-claim for $S$.

rule 28 The defence of a questioned reason-claim consists of the establishment of an apply-claim with regard to a rule that can constitute the claimed reason.

rule 29 The defence of a questioned applicable-claim with regard to rule $\mathrm{R}$ consists by default of the following two steps in the given order:

a. the establishment of the validity-claim with regard to the rule R;

b. the establishment of the claims of the conditions of R.

If the claims regarding the conditions have been established, the proponent of the applicable-claim must repeat his claim. The opponent has the choice to accept this claim, or to make an excluded-claim with regard to the rule R. If the dialogue about the excluded-claim ends by a withdrawal, or by a negative decision by the arbiter about the excluded-claim, the opponent of the applicable-claim must still accept this applicableclaim.

rule 30 The defence of a questioned abstract weight-claim for a sentence $S$ consists of the establishment of a concrete weight-claim for $S$. This concrete weight-claim must refer to all of the reasons for and against $S$ that have been established in the dialogue about $S$ until the moment that the abstract weight-claim for $S$ was made.

\section{The reasoning when a claim has been denied}

rule 31 A party whose claim has been denied can defend the questioned claim, instead of reacting to the claim of his opponent.

rule 32 If a party accepts the denial of one of his claims, the turn remains his.

rule 33 The denial of an abstract weight-claim for a sentence $S$, is defended like an abstract weight-claim against $S$.

\section{Forced acceptances and withdrawals}

rule 34 If a party is forced to accept $\sim S$, while he is committed to $S$, he must first withdraw $S$ before he accepts $\sim S$.

If a party is forced to accept $S$, while he is committed to $\sim S$, he must first withdraw $\sim S$ before he accepts $S$.

rule 35 If a party $P$ accepts an excluded-claim with respect to rule(R), he must first withdraw the sentence apply(rule(R)).

rule 36 If a party $P$ accepts an abstract weight-claim of the form outweigh(reasons_for, reasons_against, $S$ ), he must, if $S$ is an open claim of his opponent's, at the same turn accept $S$. (These two acceptances together take only one turn.) 
rule 37 If a party $P$ accepts an abstract weight-claim of the form outweigh(reasons_against, reasons_for, $S$ ), he must, if $S$ is an open claim of his opponent's, at the same turn accept $\sim S$. (These two acceptances together take only one turn.)

rule 38 If a party $P$ accepts a concrete weight-claim of the form Claim: outweigh $\left(\left(R_{p 1} \ldots R_{p n}\right)\right.$, $\left.\left(R_{c l} \ldots R_{c n}\right), S\right)$, he must, at the same turn accept an abstract weight-claim of the form outweigh(reasons_for, reasons_against, $S$ ), if this is an open claim of his opponent's, and if $R_{p 1} \ldots R_{p n}$ are the established reasons for $S$, and $R_{c l} \ldots R_{c n}$ are the established reasons against $S$. (These acceptances together take only one turn.)

rule 39 If a party $P$ accepts a concrete weight-claim of the form Claim: outweigh $\left(\left(R_{c l} \ldots R_{c n}\right)\right.$, $\left.\left(R_{p 1} \ldots R_{p n}\right), S\right)$, he must, at the same turn accept an abstract weight-claim of the form outweigh(reasons_against, reasons_for, $S$ ), if this is an open claim of his opponent's, and $R_{c l} \ldots R_{c n}$ are the established reasons against. (These acceptances together take only one turn.)

rule 40 If a party withdraws an excluded-claim with respect to rule(rule_id, rule_conditions $\Rightarrow$ rule_conclusion), he must at the same turn accept the sentence apply(rule(rule_id, rule_conditions $\Rightarrow$ rule_conclusion)) if the validity of rule(rule_id) and the conditions of this rule were already established.

rule 41 If a party accepts an apply-claim of the form Claim: apply(rule(rule_id,rule_conditions $\Rightarrow$ rule_conclusion)), where rule_conclusion is not negated, he must at the same turn accept the sentence reason(rule_conditions, rule_conclusion, pro) if this was the sentence of an open claim of his opponent's.

If a party accepts an apply-claim of the form Claim: apply(rule(rule_id,rule_conditions $\Rightarrow \sim$ rule_conclusion)), he must at the same turn accept the sentence reason(rule_conditions, rule_conclusion, con) if this was the sentence of an open claim of his opponent's.

rule 42 If a party $P$ accepts a refusal, he must withdraw the claim of the refused sentence. The same counts if the arbiter has decided in favour of the refusal.

If a dialogue about a refusal ends with a negative decision of the arbiter, or with a withdrawal of the refusal, it is the turn of the party who made the refusal. This party can make any move that would have been possible at the moment of the refusal, with the exception of the refusal itself. 


\section{REFERENCES}

Alexy, R. (1978). Theorie der juristischen Argumentation. Suhrkamp Verlag, Frankfurt am Main. Ashley, K.D. (1991). Reasoning with cases and hypotheticals in HYPO. International Journal of Man-Machine Studies, vol. 34, p. 753-796.

Ashley, K.D. and E.L. Rissland (1988). Waiting on Weighting: A Symblic Least Commitment Approach. Proceeding AAAI-88, American Association for Artificial Intelligence, p. 239-244. Ashley, K.D. and E.L. Rissland (1987). But, See, Accord: Generating Blue Book Citations in HYPO, Proceedings of the first International Conference on Artificial Intelligence and Law, ACM, New York, p. 67-74.

Barth, E.M. and E.C.W. Krabbe (1982). From Axiom to Dialogue. Walter de Gruyter, Berlin, New York.

Bench-Capon, T.J.M., P.E.S. Dunne and P.H. Leng (1991). Interacting with Knowledge Systems Through Dialogue Games. Proceedings of the 11th Annual Conference on Expert Systems and their Applications (vol. 1), p. 123-130. Avignon.

Berman, D.H. and C.D. Hafner (1987). Indeterminacy: A Challenge to Logic-based Models of Legal Reasoning, Yearbook of Law, Computers and Technology, vol 3., p. 1-35.

Brown, H.I. (1988). Rationality. Routledge, London and New York.

Dworkin, R. (1978). Taking Rights Seriously, 2nd ed., Duckworth, London.

Dworkin, R. (1986). Laws Empire, Fontana, London.

Gardner, A. von der Lieth (1987). An Artificial Intelligence Approach to Legal Reasoning, MIT Press, Cambridge Mass.

Geffner, H. and J. Pearl (1992). Conditional entailment: bridging two approaches to default reasoning, Artificial Intelligence 53, p.209-244.

Ginsberg, M. (ed.) (1987). Readings in Nonmonotonic Reasoning, Morgan Kaufmann Publishers, Palo Alto.

Gordon, Th. F. (1991), An abductive theory of legal issues, International Journal of ManMachine Studies, vol. 35, p. 95-118.

Gordon, Th. F. (1993a), The Pleadings Game - Formalizing Procedural Justice, Proc. of the Fourth International Conference on Artificial Intelligence and Law, Amsterdam, p. 10-19.

Gordon, Th. F. (1993b), The Pleadings Game. An Artificial Intelligence Model of Procedural Justice. PhD thesis, Darmstadt.

Haan, N. den (1993). Towards support for drafting legislation. J.S. Svensson, J.G.J. Wassink and B. van Buggenhout eds. Legal knowledge based systems. Intelligent Tools for Drafting Legislation, Computer Supported Comparison of Law, Koninklijke Vermande B.V., Lelystad, p. 23-30.

Haersolte, R.A.V. van (1975). Monoloog met mijn schuldeiser, De mens en het zijne, Tjeenk Willink, Zwolle 1984, p. 146-164.

Hage, J.C. (1992). Redeneren met de strekking van rechtsregels. (Reasoning with the purpose of rules) (H. de Swaan Arons, H. Koppelaar and E.J. H. Kerckhoffs eds.) Proceedings NAIC '92, Delft, p. 43-52. 
Hage, J.C. (1993). Monological Reason Based Logic. Proceedings of the Fourth International Conference on Law and Artificial Intelligence, ACM-press, Amsterdam, p. 30-39.

Hage, J.C., Span, G.P.J. and Lodder, A.R. (1992), A Dialogical Model of Legal Reasoning, in Grütters, C.A.F.M., J.A.P.J. Breuker, H.J. Van Den Herik, A.H.J. Schmidt, and C.N.J. de Vey Mestdagh (eds.), Legal Knowledge Based Systems: Information Technology and Law , JURIX '92, Koninklijke Vermande, Lelystad, NL, 1992.

Hart, H.L.A. (1958). Positivism and the Separation of Law and Morals, Essays in Jurisprudence and Philosophy, (H.L.A. Hart), Clarendon Press, Oxford 1983, p.49-87.

Hart, H.L.A. (1967). Problems of the Philosophy of Law, Essays in Jurisprudence and Philosophy, Clarendon Press, Oxford 1983, p. 88-119.

Hart, H.L.A. (1961). The Concept of Law. Clarendon Press, Oxford.

Kordelaar, P. (1993). Supporting the drafting of a new Dutch national assistance act with Expertisze, J.S. Svensson, J.G.J. Wassink and B. van Buggenhout eds. Legal knowledge based systems. Intelligent Tools for Drafting Legislation, Computer Supported Comparison of Law, Koninklijke Vermande B.V., Lelystad, p.95-106.

Kuhn. T.S. (1970). The Structure of Scientific Revolutions. 2nd ed. University of Chicago Press. Lorenzen, P. and Lorenz, K. (1978). Dialogische Logik, Wissenschafliche Buchgesellschaft, Darmstadt.

Louie, R. and W. Chen (1992). An Argument Game. Technical Report WUCS-92-47. Dept. of Computer Science, Washington University.

MacCormick, D.N. and O. Weinberger (1987), An Institutional Theory of Law, Reidel, Dordrecht etc.

Mackenzie, J.D. (1979). Question-begging in non-cumulative systems. Journal of Philosophical Logic, 8, p. 159-177.

Mead, G.H. (1934), Mind, Self \& Society, The University of Chicago Press, Chicago and London. Newell, A. (1990). Unified Theories of Cognition, Harvard University Press, Cambridge Mass., London.

Nitta, K., S. Wong, and Y. Othake (1993). A Computational Model for Trial Reasoning.

Proceedings of the Fourth International Conference on Artificial Intelligence and Law, ACM

Press, p. 20-29.

Perelman, Ch. and Olbrechts-Tyteca, L. (1969). The New Rhetoric; a Treatise on Argumentation. University of Notre Dame Press, Notre Dame, London.

Pollock, J.L. (1987). Defeasible Reasoning. Cognitive Science 11, p. 481-518.

Rawls, J. (1972). A Theory of Justice, Oxford University Press, Oxford.

Raz, J. (1975). Practical Reason and Norms, Hutchinson, London.

Rissland, E.L. and Skalak, D.B. (1991), CABARET: rule interpretation in a hybrid structure, International Journal for Man-Machine Studies, vol. 34, p. 839-887.

Rorty, R. (1980). Philosophy and the mirror of nature, Princeton University Press, Princeton.

Ruiter, D.W.P. (1993) Institutional legal facts; Legal Powers and their Effects. Kluwer Academic Publishers, Dordrecht, Boston, London.

Searle, J.R. (1969). Speech acts; An essay in the philosophy of language, Cambridge University Press. 
Skalak, D.B. and Rissland, E.L. (1992). Arguments and Cases: An Inevitable Intertwining. Artificial intelligence and Law, vol 1 nr. 1, p. 3-44.

Susskind, R.E. (1987). Expert Systems in Law, A Jurisprudential Inquiry, Clarendon Press, Oxford.

Svensson, J.S. (1993). Kennisgebaseerde microsimulatie. (Knowledge Based Microsimulation) Dissertatie Enschede.

Toulmin, S.E. (1958). The Uses of Argument, Cambridge University Press, London, New York. Vreeswijk, G.A.W. (1993). Studies in Defeasible Argumentation. PhD-thesis, Amsterdam.

Waismann, F. (1949). Verifiability. A. Flew ed., Logic and language, 1st series, Oxford 1949.

Witteveen, W.J. (1988). De retoriek in het recht, W.E.J. Tjeenk Willink, Zwolle. 